\title{
Experimental constraints on volcanic ash generation and clast morphometrics in pyroclastic density currents and granular flows
}

\author{
Adrian J. Hornby*, Ulrich Kueppers, Benedikt Maurer, \\ Carina Poetsch, Donald B. Dingwell \\ Earth and Environmental Sciences, Ludwig-Maximilians-Universität (LMU), Theresienstr. 41/III, 80333 Munich, Germany
}

\begin{abstract}
Pyroclastic density currents (PDCs) are a prominent hazard of volcanic activity; however, fully quantitative observations are lacking and little direct evidence exists to constrain the parameters controlling ash production and runout. Here, we use rotary tumbling experiments to investigate ash generation efficiency and clast morphometrics in the dense basal flow of PDCs. We observe greater ash generation with periodic ash removal and with higher starting mass. By scaling to the bed height and clast diameter we obtain a general description for ash production in all experiments as a function of flow distance that we parameterise in dimensionless space. We also show that ash production correlates with clast shape changes and with the Inertial number for our experiments. This work introduces some of the first systematic and generalizable experimental parameterizations of ash production and clast evolution in PDCs and should advance the ability to understand flow mobility and associated hazards.
\end{abstract}

Keywords: Abrasion; Comminution; Grain shape;

Tephra; Pyroclasts; Volcanic hazards

\section{INTRODUCTION}

Pyroclastic density currents (PDCs) are among the most hazardous and unpredictable phenomena of explosive volcanic eruptions. They can occur either due to the gravitational collapse of an eruption column, or through collapse of lava flow or dome material [Branney and Kokelaar 2003; Sato et al. 1992]. PDCs are highly energetic gas-fluidised flows whose clasts consist of those derived from primary volcanic material, from lithic materials and from the flow substrate. They are predominantly gravity-driven with flow paths thus determined dominantly by topography and surface roughness. Although no direct observations exist, PDCs are usually assumed to be vertically stratified, possessing a denser basal layer (bedload) and a more dilute overriding ash cloud [Breard et al. 2016; Denlinger 1987; Valentine 1987]. PDC particle concentrations, grain size distributions, air entrainment, permeability and pressurisation together with their dynamic variations are subjects of ongoing research. PDCs are capable of propagating significant distances, exhibiting the abilities to climb topography and to advance over open water. Remarkably, actuarial analysis collected from global eruption records between 1500 and 2017 CE indicates that PDCs have been responsible for the greatest number of direct fatalities of all volcanic hazards at distances $5-15 \mathrm{~km}$ from the eruption cen-

\footnotetext{
${ }^{*}$ Corresponding author: adrianhornby@gmail.com
}

tre, while lahars and tsunamis caused higher fatalities at greater distances [Brown et al. 2017]. Flow mobility is controlled by the amount, size, and density of cargo [Calder et al. 1999; Gray and Kokelaar 2010], by air entrainment efficiency and by bulk permeability, as determined by the suspended fine ash [Cagnoli and Romano 2012; Fauria et al. 2016; Lube et al. 2019]; all of these can be dramatically modulated by the channel topography and elevation change [Andrews and Manga 2011; Douillet et al. 2013]. During transport, particleparticle as well as particle-ground interactions are a constant source of fine particle generation; this replenishment modulates the substantial coarsening in the basal layer due to elutriation of fine ash. The competition between particle production, entrainment, and deposition determines the mobility and runout distance of a PDC [Branney and Kokelaar 2003; Caballero et al. 2014; Fauria et al. 2016; Sulpizio et al. 2014]. Depending on the energy and density of the PDC, particles may be 1) deposited, 2) partitioned to a higher-density bedload dominated by particle interactions, 3 ) entrained in a dilute current dominated by turbulent suspension, or 4) lofted by elutriation to form an overriding ash cloud, that may also detach as a phoenix cloud [Engwell and Eychenne 2016; Rose and Durant 2009]. It has been estimated that co-PDC ash production (ash production during PDC transport) may form up to $75 \mathrm{vol} . \%$ of the total ash deposited in large eruptions [Dartevelle et al. 2002; Marti et al. 2016]. 
Ash produced in PDCs has a distinctive densitydriven compositional segregation between co-PDC elutriated ash that is typically enriched in glass, cristobalite and felsic microlites [Freundt and Schmincke 1992; Hornby et al. 2019; Horwell et al. 2001], and higher-density crystal-enriched ash deposited in the PDC channel [Sparks and Walker 1977]. Co-PDC ash also has a finer grain size distribution than ash generated by magmatic fragmentation [Engwell and Eychenne 2016; Evans et al. 2009]; together, these properties can significantly increase the environmental impact and health hazard presented by co-PDC ash in comparison to air-fall ash from magmatic fragmentation [Ayris and Delmelle 2012; Horwell and Baxter 2006; Jones and BéruBé 2011].

Through comparisons with detailed studies and interpretation of PDC deposits in the field [Caballero et al. 2014; Calder et al. 2000; Douillet et al. 2013; Sarocchi et al. 2011; Suzuki-Kamata and Kamata 1990; Taddeucci and Palladino 2002], substantial advances in understanding fragmentation and deposition processes have been made. While PDC transport distance is generally positively correlated with probability for mechanical abrasion, there is no direct relationship with grain size distribution (GSD). Several deposits 2.8$10 \mathrm{~km}$ from the vent have been observed to be poorly sorted and rich in cm-sized clasts, such as the PDC deposits of the August 2006 eruption of Tungurahua volcano, [Douillet et al. 2013] and the block-and-ash flow deposits of the July 2015 eruption of Volcán de Colima, Mexico [Macorps et al. 2018]. Ash production occurs via comminution and breakage of the clasts in the flow resulting in size reduction and rounding [Calder et al. 2000; Manga et al. 2011; Walker 1971] that in turn affect the flow dynamics [Caballero et al. 2014; Dellino et al. 2010] and the capacity for subsequent ash generation. Direct observations of active PDCs is limited because of their energetic nature and general opacity. Accordingly, experimental studies have made a major contribution to enhanced understanding of flow and depositional processes of PDCs. Here, we use measurements of clast and ash properties during experiments to better understand the relationship between ash production, particle morphometrics and rheology.

A common experimental method to study ash production in PDCs and the development of clast shape is through tumbling and milling experiments [Buckland et al. 2018; Caballero et al. 2012; Jones et al. 2016; Kueppers et al. 2012; Manga et al. 2011; Mueller et al. 2015; Patel et al. 2013]. These studies have shown that clasts are progressively rounded by abrasion, and that the rate of ash production exhibits a non-linear decrease with tumbling distance. The rotating drum method has been widely used to investigate the dynamics of debris flows [Félix et al. 2007; GDR MiDi 2004; Gray and Kokelaar 2010; Santos et al. 2016] and their frictional behaviour [Forterre and Pouliquen 2008; Govender 2016; Kelfoun et al. 2009] as well as for the comminution of ores [Cleary and Morrison 2016; King 2001]. Particle dynamics within the rotating drum, together with appropriate scaling functions and bulk frictional behaviour, have been constrained for the simple experimental materials (e.g. monodisperse spherical hard particles), but laws for non-ideal materials and setups are not well-established. In particular, for PDCs, the in-situ production of ash is poorly understood as a function of the flow properties.

We use two tumbling apparatuses to simulate ash production during flow of a surface layer over a relatively static base layer. This method combines particle production through abrasion with that from collision processes, which best matches the inferred particle interactions in the dense basal regime and the flow head of PDCs, where runout is ultimately determined [Andrews and Manga 2011]. Similar apparatuses are used in the mineral processing [Cleary and Morrison 2016] and hydrology [Novák-Szabó et al. 2018] communities. We investigate the time- or runout-dependent evolution of ash production efficiency and grain size and link this to the changing properties of parent clasts and the energy regime in the tumbling system. We vary the degree of collisional and total energy in our experimental systems by (i) changing the density and mass of the initial clast population, (ii) changing the size and material of the drum in the tumbling apparatus, and/or (iii) removing the ash from the drum at time steps. By making these comparisons we can constrain the effects of material and experimental properties on ash production and begin to quantify and describe the effects of clast breakage as well as abrasion on the production and efficiency of ash generation with progressive PDC runout. A better understanding of the proportions of coarse and fine clasts as well as the mechanisms and efficiency of ash generation can help to assess direct and indirect hazards (e.g. co-PDC ash-related) of PDCs. Furthermore, recognition and estimation of flow parameters and ash production from PDC deposits of past eruptions contribute to hazard assessment and modelling of ongoing or future eruptions [Marti et al. 2016; Ogburn and Calder 2017; Sigurdsson and Carey 1989; Wilson et al. 2014].

\section{Methods}

\subsection{Nomenclature}

We use the notation given in Table 1 in this study, with subscript to identify different subjects. The subscript identifiers are included in the "Description" column of Table 1.

\subsection{Tumbling experiments}

In this study, tumbling experiments were carried out in two separate devices; a smaller, cylindrical hard gum 
Table 1 - Notation and terms used.

\begin{tabular}{|c|c|c|c|}
\hline Terminology & Description & Units & Notes \& references \\
\hline$r ; D$ & Radius; Diameter of the drum & $\mathrm{m}$ & \\
\hline$w$ & Length of the drum & $\mathrm{m}$ & \\
\hline$S ; \mathrm{t}$ & Tumbling distance; Tumbling time & $\mathrm{s}$ & \\
\hline$\omega$ & Angular velocity of the drum & $\mathrm{s}^{-1}$ & $2 \pi / T$ \\
\hline$g$ & Gravitational acceleration & $\mathrm{ms}^{-2}$ & 9.81 used herein \\
\hline $\mathrm{Fr}$ & Froude number & & $F r=\omega \sqrt{D / 2 g}$ \\
\hline$h$ & Bedload height at the back wall & $\mathrm{m}$ & \\
\hline$h_{f}$ & Height of the flowing surface layer & $\mathrm{m}$ & \\
\hline$L$ & Half-length of the chord of the bed & $\mathrm{m}$ & Mellmann [2001] \\
\hline$W$ & Width of the bedload & $\mathrm{m}$ & \\
\hline$\Phi$ & Logarithmic scale for grain size & & $-\log _{2} d$ \\
\hline$m$ & Mass (p: particle; f: fill) & Kg or g & \\
\hline$d$ & Geometric mean diameter of clasts (Equation 1) & $\mathrm{mm}$ or $\Phi$ & McCammon [1962] \\
\hline$\sigma$ & Particle size sorting (Equation 2) & & McCammon [1962] \\
\hline$M_{d}$ & Equivalent spherical volume & $\mathrm{cm}^{3}$ & $4 / 3 \pi(d / 2)^{3}$ \\
\hline$\phi$ & Clast porosity & $\%$ & \\
\hline$\rho$ & Density (b: clast bulk, s: clast solid, f: bedload bulk) & $\mathrm{g} \mathrm{cm}^{-3}$ & \\
\hline$\eta$ & Solid packing fraction & & Volume fraction \\
\hline$V$ & Volume (f: fill, d: drum c: clast) & $\mathrm{cm}^{3}$ & Assuming loose packing \\
\hline$\theta$ & Filling angle (half bed angle) & radians & Mellmann [2001] \\
\hline$f$ & Filling fraction & & $V_{f} / V_{d}$ \\
\hline$f_{a}$ & Filling area on the back wall & $\mathrm{m}^{2}$ & \\
\hline$\Theta$ & Angle of repose (st: static, dyn: dynamic) & $\circ$ & Measured in drum \\
\hline Q & Flow rate & $\mathrm{m}^{2} \mathrm{~s}^{-1}$ & GDR MiDi [2004] \\
\hline Q* & Normalised flow rate (Equations 4 and 5) & & GDR MiDi [2004] \\
\hline$u$ & Bedload velocity (s: surface, b: base) & $\mathrm{m} \mathrm{s}^{-1}$ & \\
\hline$P$ & Pressure & $\mathrm{Pa}$ & $m g \cos \Theta$ \\
\hline$\dot{\gamma}$ & Shear rate & $s^{-1}$ & $\delta u / h_{f}$ \\
\hline$I$ & Inertial number (Equation 6) & & GDR MiDi [2004] \\
\hline & 2D projected particle area; Perimeter & $\mu \mathrm{m}^{2} ; \mu \mathrm{m}$ & \\
\hline Form factor & Particle circularity or "compactness" & & $4 \pi * a / p^{2}$ \\
\hline Solidity & Measure of particle concavity & & a/area of convex hull \\
\hline$x, y, z$ & Short, intermediate, \& long clast lengths & $\mathrm{mm}$ & Calliper measurements \\
\hline Elongation & Particle elongation $(y / z)$ & & Bagheri and Bonadonna [2016 \\
\hline Flatness & Particle flatness $(x / z)$ & & Bagheri and Bonadonna [2016 \\
\hline$\alpha$ & Internal fiction angle & $\circ$ & \\
\hline$\mu_{i n t}$ & Internal friction coefficient & & \\
\hline$e$ & Coefficient of restitution & & \\
\hline
\end{tabular}

tumbler with a horizontally mounted drum of length $(w) 10 \mathrm{~cm}$ and radius $(r) 5 \mathrm{~cm}$ (see Kueppers et al. [2012] for detailed description), and a larger, industrial cement mixer (SM145 from Lescha) for both room temperature (Figure 1A) and elevated temperature experiments (Figure 1B). The drum of the cement mixer ( $w$ $=54 \mathrm{~cm}$ ) has complex geometry, with a maximum radius $r=32 \mathrm{~cm}$ tapering to $20.5 \mathrm{~cm}$ at the front, and a total volume of $0.14 \mathrm{~m}^{3}$ (Figure 1C). The drum was inclined to $57^{\circ}$ from the vertical, allowing up to $2 \mathrm{~kg}$ of pumice lapilli (up to 10,000 particles representing up to 8.75 litres of loose tephra) to remain in the wider part of the drum during tumbling and was kept constant for all experiments. The cement mixer drum was unpainted to avoid sample contamination during experiments. The rotational velocity was adjusted with a retrofitted frequency regulator (FUS E5/3E5, Peter Electronics). The drum has vented interior blades that do not reach to the base; these did not interact with clasts in the $1 \mathrm{~kg}$ and $0.5 \mathrm{~kg}$ runs and only weakly disrupted 
the load in some $2 \mathrm{~kg}$ experiments. The sensitivity of the rotation rate to load and frequency was systematically measured and had no deviation below $20 \mathrm{~kg}$ load at maximum velocity.

Rotation velocity was kept constant for all experiments, at approximately 24 rotations per minute ( $\mathrm{rpm})$ for the cement mixer and $49 \mathrm{rpm}$ for the small tumbler, equating to $0.82 \mathrm{~m} \mathrm{~s}^{-1}$ and $0.26 \mathrm{~m} \mathrm{~s}^{-1}$, respectively [Kueppers et al. 2012]. Tumbling distance has been calculated using the maximum drum diameter and experiment duration. Both devices were sealed during the experiments to avoid fine particle loss. During tumbling, the particle bed was inclined above the angle of repose, leading to a flowing layer where clasts had quasi-constant rolling motion with subordinate saltation and sliding (Figure 1D). Fine particles are assumed to be produced primarily by attrition between individual clasts. Mass loss due to fine ash lofting was mitigated by allowing a period for settling (ca. 10 minutes) before opening the drum.

Each experiment started with a new batch of angular lapilli (>4 mm diameter) and lasted for 120 minutes. The tumbling was interrupted four times (after 15, 30, 45 , and 60 minutes, respectively). After each of the five time steps, the drum was emptied, and the amount of fine particles was constrained by dry-sieving. In most experiments, a small aliquot of the fines was sampled for grain size distribution. Additionally, photographs were taken of the lapilli clasts at each time interval, giving five sets of data for each experiment after 15, $30,45,60$, and 120 minutes, respectively (see Subsection 2.3). For some experiments in the large tumbler, video footage was taken at the onset of tumbling with the lid removed; in a few others, the dimensions of the pre-weighed starting load inside the drum were measured and photographs were taken of the static load after a short period of tumbling.

We performed sets of experiments at two different conditions:

I. Lapilli and ash returned to the drum for further tumbling after $15,30,45$, and 60 minutes;

II. Only lapilli returned to the drum after each time step; ash removed and stored separately after 15 , 30,45 , and 60 minutes.

Additionally, two high temperature experiments were carried out in the large tumbler. Heat was provided by two propane space-heater gas burners. A thermocouple was inserted through the ceramic lid and suspended in the centre of the drum. Before each run, the empty drum was preheated while rotating for at least one hour to reach a stable air temperature of $130^{\circ} \mathrm{C}$. Sample material was preheated in a box furnace to $200{ }^{\circ} \mathrm{C}$ and left for up to one hour to thermally equilibrate before adding to the drum and starting the experiment. Due to the heating constraints, material was taken out after 30 minutes, then new material was heated up and taken out after 60 minutes. All experiments are summarised in Table 2.

\subsection{Starting Material}

We used three lapilli samples (Figure 2), from 1) Laacher See volcano, East Eifel volcanic field, Germany (LSB), 2) Sete Cidades volcano on São Miguel Island, Azores, Portugal (7C), and 3) Valentano scoria cone, Italy (VAL). Shape and size parameters were analysed for 100 representative clasts (Figure 2). Additionally, petrophysical investigations were performed.

1) The Laacher See pumice (LSB) clasts derive from proximal-medial fall deposits of the $13 \mathrm{ka}$ Plinian Laacher See eruption. The composition is phonolitic, containing a high fraction of phonolitic glassy groundmass (>90 vol.\%) with phenocrysts of sanidine and accessory mafic minerals [Van den Bogaard and Schmincke 1985]. Vesicles are predominantly round and $<1.5 \mathrm{~mm}$ in size. LSB was processed by ROTEC $^{\circledR} \mathrm{GmbH}$, including washing and grain-size separation. The initial clast size was 6-20 $\mathrm{mm}$ with predominantly angular, at times slightly edge-modified shapes (Figure 2A).

2) The Sete Cidades pumice (7C) clasts were collected from proximal fall deposits of the $16 \mathrm{ka}$ eruption of Sete Cidades volcano [Porreca et al. 2018]. The trachytic clasts are largely aphyric (Figure 4 in Kueppers et al. [2019]). Texturally, two vesicle populations can be distinguished $(<1.5 \mathrm{~mm}$ and round; up to $5 \mathrm{~mm}$ and aspect ratio up to $3: 1$ ). Unwashed and angular 5-40 $\mathrm{mm}$ clasts were selected for tumbling experiments (Figure 2B).

3) The scoriaceous clasts (VAL) were collected directly from the Valentano scoria cone, made up from dm-thick, stratified, clast-supported, nonwelded layers. The basaltic clasts contain 2-5\% phenocrysts of clinopyroxene, olivine, plagioclase, and phlogopite from 200-500 $\mu \mathrm{m}$ and 2-5\% microlites [Perugini et al. 2011] and are substantially denser than LSB or 7C. We selected 4-16 mm clasts from multiple stratigraphic levels (Figure 2C) that show similar crystal fractions and textures.

\subsection{Particle size and shape analysis}

Abrasion efficiency was quantified as weight fraction of particles $<2 \mathrm{~mm}$ via dry sieving. Aliquots $(2-3 \mathrm{~g})$ of the fine fraction $(<2 \mathrm{~mm})$ of each time interval of each experiment were further characterised for size distribution and shape parameters in a Bettersizer M3 (3P Instruments). The refractive index of the samples at $532 \mathrm{~nm}$ wavelength was measured and used as a fixed parameter for each sample. Three to five repetitive measurements of the same sample were performed to 

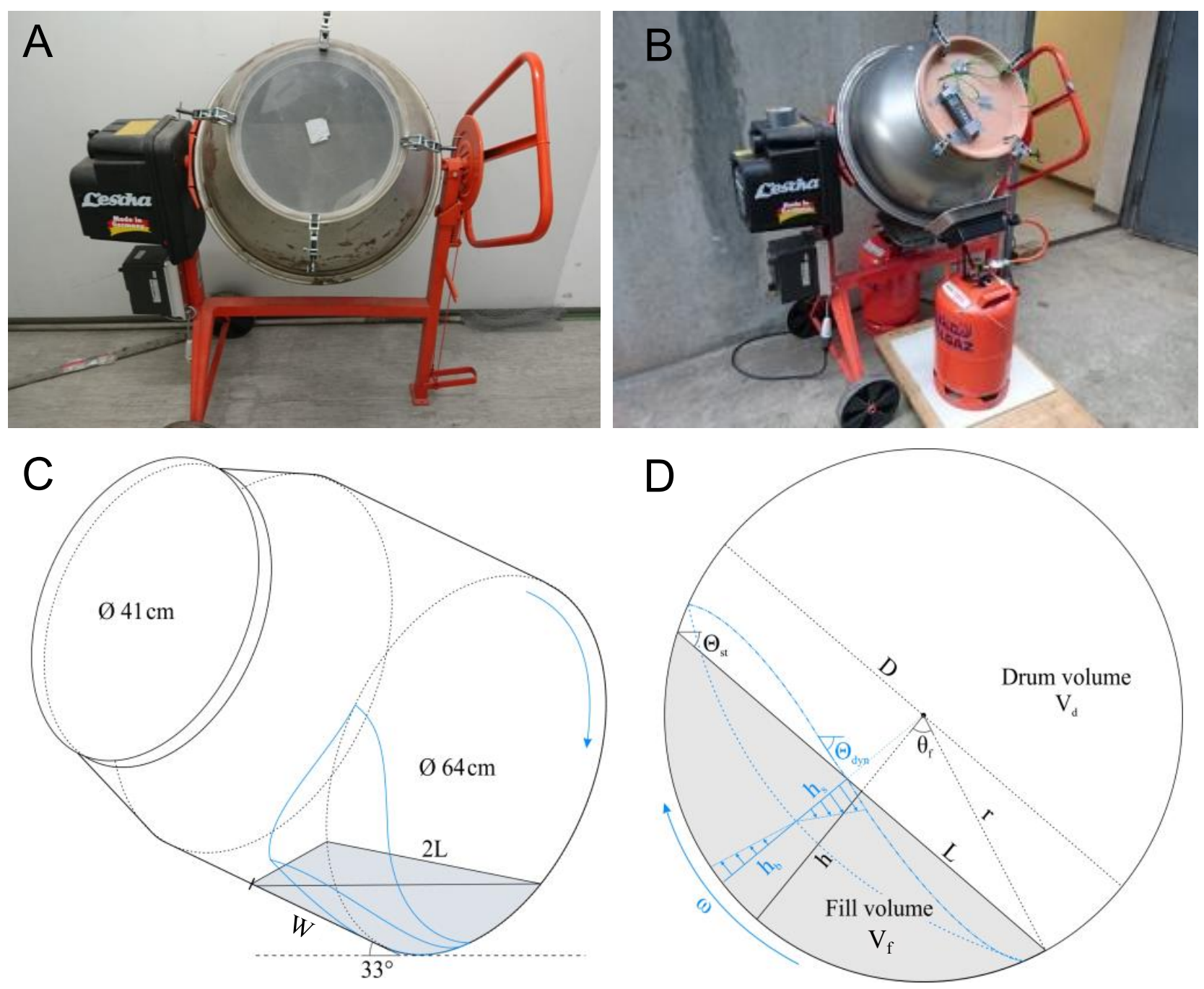

Figure 1: Experimental apparatus. The cement mixer used in this study for abrasion experiments at [A] ambient conditions and $[\mathrm{B}]$ elevated temperature. The use of two external gas burners allowed for in-drum temperatures up to $130{ }^{\circ} \mathrm{C}$. A ceramic lid was used with a K-type thermocouple to monitor interior air temperature. Setup of the large drum with $[\mathrm{C}]$ the drum and fill dimensions and [D] the notation used to describe the bedload properties and dynamics on the backwall of the drum. The grey fill in [B] is shown for a bedload at rest following tumbling; properties during tumbling are shown in blue outline in both panels.

Table 2 - The experiment run conditions and their corresponding abbreviations are listed for all 21 experiments. " $x$ " indicates experiments performed once. " $x \times$ " indicates experiments performed two times. Runs with $0.5,1$, and $2 \mathrm{~kg}$ starting material were performed in the large setup, whereas the small setup was used for the $0.05 \mathrm{~kg}$ experiments.

\begin{tabular}{|c|c|c|c|c|c|c|c|c|c|c|c|c|c|c|}
\hline \multicolumn{3}{|c|}{ Parameters } & \multicolumn{4}{|c|}{ Laacher See Pumice (LSB) } & \multicolumn{4}{|c|}{ Sete Cidades Pumice (7C) } & \multicolumn{4}{|c|}{ Valentano Scoria (VAL) } \\
\hline \multirow{2}{*}{ Run type } & \multirow{2}{*}{$T\left[{ }^{\circ} \mathrm{C}\right]$} & \multirow{2}{*}{$t_{t}[\mathrm{~min}]$} & \multicolumn{12}{|c|}{$m_{f}[\mathrm{~kg}]$} \\
\hline & & & 2 & 1 & 0.5 & 0.05 & 2 & 1 & 0.5 & 0.05 & 2 & 1 & 0.5 & 0.05 \\
\hline I & 25 & $15,30,45,60,120$ & $x x$ & $x$ & $x$ & $x x$ & $x$ & $x$ & & $x$ & $x x$ & $x$ & & $x$ \\
\hline II & 25 & $15,30,45,60,120$ & $x$ & $x$ & $x$ & $\times$ & $x$ & & & $x$ & $x$ & & & \\
\hline HT & 130 & 30,60 & $x$ & & & & & & & & & & & \\
\hline
\end{tabular}




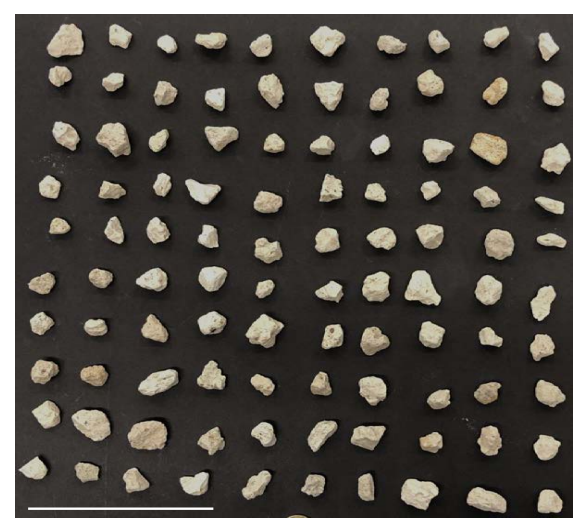

A Laacher See (LSB), Eifel, DE

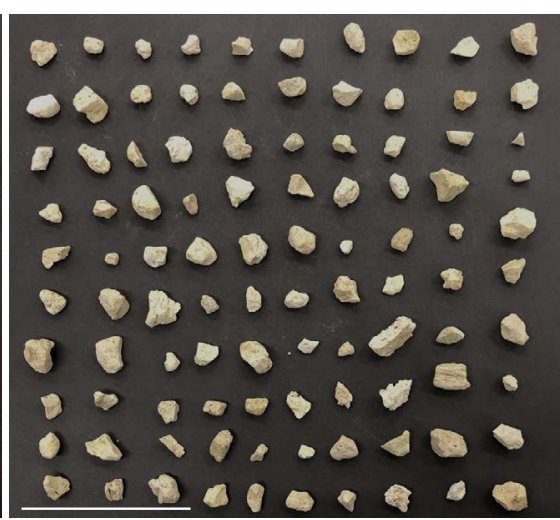

B Sete Cidades (7C), São Miguel, PT

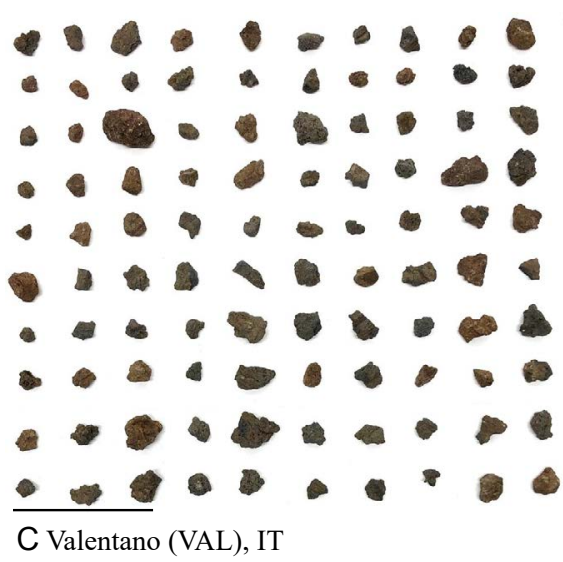

Figure 2: Photographs of 100 representative clasts of the starting material for [A] Laacher See, [B] Sete Cidades and $[C]$ Valentano. Black/white background allowed for better contrast as images were processed to obtain size and shape data. The bottom-left scale bar (white or black line) is $10 \mathrm{~cm}$.

Table 3 - Average initial clast properties of the starting materials. Clast dimensions and shape factors were calculated from image analysis, while bulk density and porosity was calculated from calliper measurements of post-experimental clasts and pycnometer measurements of finely milled material. Intrinsic frictional properties and the coefficient of restitution were estimated from literature values.

\begin{tabular}{rcccccccccccccc}
\hline Sample & $M_{d}$ & $d$ & $\sigma$ & $D / d$ & $m[\mathrm{~g}]$ & Solidity & $\begin{array}{c}\text { Form } \\
\text { factor }\end{array}$ & ${ }^{*} \rho_{b}$ & $\rho_{s}$ & $\phi$ & $\Theta_{s t}$ & $\mu_{\text {int }}$ & $\alpha$ & $e$ \\
\hline LSB init & 1.16 & 13.03 & 0.26 & 49 & 0.60 & 0.96 & 0.86 & 0.51 & 2.48 & 79.12 & 45 & 0.8 & 56 & 0.01 \\
7C init & 1.83 & 15.18 & 0.40 & 42 & 0.88 & 0.96 & 0.86 & 0.48 & 2.46 & 80.40 & 40 & 0.8 & 56 & 0.01 \\
VAL init & 1.49 & 14.17 & 0.48 & 45 & 1.85 & 0.94 & 0.80 & 1.24 & 2.95 & 57.81 & 41 & 0.6 & 41 & \\
\hline
\end{tabular}

* Bulk density calculated from calliper measurements of post-experimental clasts (see Subsection 2.5). Reference values for pumice and scoria are used as constraints for the experimental materials. For LSB and 7C pumice: $\alpha$ [Cagnoli 2004]; $\mu_{\text {int }}$ [He and Senetakis 2019; Samuelson et al. 2008]; $e$ [Elskamp et al. 2017; Mueller et al. 2015]; Reference values for VAL scoria: $\alpha$ [Agustian and Goto 2008]; $\mu_{\text {int }}$ [Sandeep and Senetakis 2018].

ensure accuracy, under ultrasonic dispersion to prevent aggregation. All percentile values and full grain size distribution reports are listed in the online repository [Hornby et al. 2020], together with the mean, median and standard deviation.

The time-dependent shape evolution of lapilli clasts was constrained via image analysis of the projected area of the clasts from digital photographs (Figure 2). To this end, 100 randomly selected clasts were photographed after every experimental time step. We used a set of ImageJ macros to 1) scale, crop, and threshold the photos, using the MorphoLibJ plugin [Legland et al. 2016] to reduce noise; 2) calculate morphometrics based on measurements from the Shape Filter plugin [Wagner and Lipinski 2013], following the methods described in Guimarães et al. [2019], and 3) select and compile specific morphology data using the Read and Write Excel plugin. The cropped colour images, cropped binary images, raw morphometric results and ImageJ macros used for thresholding and measurement are included in the online repository [Hornby et al. 2020]. We mea- sured the projected particle area and calculated the equivalent spherical diameter $(D)$ in $\mathrm{mm}$ to compare directly against the laser particle size distribution measurements. All grain size values were also converted to phi $(\Phi)$ scale, where $\Phi=-\log _{2} D$ (with $D$ in $\mathrm{mm}$ ). We use the graphic measures of McCammon [1962] to estimate the arithmetic median grain diameter $(d)$ and the sorting $(\sigma)$, where

$$
d=\frac{\Phi_{10}+\Phi_{30}+\Phi_{50}+\Phi_{70}+\Phi_{90}}{5}
$$

and

$$
\sigma=\frac{\left(\Phi_{70}+\Phi_{80}+\Phi_{90}+\Phi_{97}-\Phi_{3}-\Phi_{10}-\Phi_{20}-\Phi_{30}\right)}{9.1}
$$

rather than the Folk and Ward methods [Folk and Ward 1957; Folk 1966], since this includes a contribution from coarser grain sizes which are important for some samples. Of the measured shape factors we present the aspect ratio, solidity, and form factor (also called compactness or Cox circularity), matching those used 
widely in the literature [Buckland et al. 2018; Manga et al. 2011]. We present shape factor data in box plots describing the interquartile range (IQR; i.e. the $25^{\text {th }}-75^{\text {th }}$ percentile range), with whiskers defining the minimum and maximum values and suspected outliers $(>1.5 \times$ IQR) marked as points. Shape data represent at least 100 data points, while some repeated measurements and many of the $2 \mathrm{~kg}$ experiments contain data from more lapilli ( $<450$ points).

\subsection{Material properties}

For all samples, we measured four parameters:

1. Dense rock equivalent density, $\rho_{s}$, was measured by helium pycnometry (Ultrapyc 1200e) on finely milled samples.

2. Average clast mass was measured by either counting the number of clasts in $50 \mathrm{~g}$ or measuring the total mass of a known number of clasts. The weighted average of several sets of measurements was used to obtain an average, with the number of particles in each average noted. Median values are reported to avoid excessive skewing by large clasts.

3. The principal axes of 50 clasts, randomly selected from each sample following 120 minutes tumbling, were measured with a calliper. We report simple shape factors describing elongation and flatness. We used the median values for each axis to calculate an average volume, $V_{c}$, based on a three-axial ellipsoid. The average grain diameter was then estimated by calculating an equivalent spherical diameter in $\Phi$ units. We calculated the average diameter and sorting using the methods described in Subsection 2.4. The bulk density, $\rho_{b u l k}$, and the porosity, $\phi$, were calculated using the average mass and volume.

4. Finally, we estimated the bulk volume of clasts in the starting load using a solid packing fraction of 0.45 . This value is slightly lower than a close packing of 'fairly angular' quartz [Brouwers 2006] and a loose packing of frictional ellipses [Delaney et al. 2011] and consistent with experimental observation of basal flow density [Rowley et al. 2014]. We measured the static angle of repose from bedloads in the drum after a short period of tumbling. Change in the angle of repose with ash production is not investigated here.

All data are available in the online data repository [Hornby et al. 2020].

\section{RESULTS}

3.1 Petrophysical properties and morphologies of the starting material

We combine data from 350 to 600 clasts for each sample, photographed prior to experiments (Figure 2) to characterise their size and shape characteristics (Table 3). The initial aspect ratio of all samples falls within error, with a mean value of 0.74 and standard deviation of 0.1. Average form factor and solidity values for LSB and 7C samples are identical at 0.86 and 0.96 , respectively, while a lower value of 0.84 for both properties is found for VAL. In general, LSB and 7C samples may be considered as equivalent in shape, while the VAL scoria is slightly more angular and less rounded. All starting clasts are blocky, with straight to convex faces. Clast sizes vary, with median $d$ of $13 \mathrm{~mm}$ for LSB, $15.2 \mathrm{~mm}$ for 7C and $14.2 \mathrm{~mm}$ for VAL, with corresponding variability in average volumes. These clast sizes give clastdrum scaling values $(D / d)$ of $42-49$ for the large apparatus. LSB samples are very well sorted $(0.26)$ while 7C and VAL samples are moderately well to well sorted (values of 0.4 and 0.48 , respectively). LSB and 7C clasts also have comparable bulk and solid density, while VAL clasts have bulk density more than double that of the pumice clasts, at $1.31 \mathrm{~g} \mathrm{~cm}^{-3}$. This is partly due to the higher solid density of the VAL scoria, as well as lower average porosity ( $58 \%$ vs. $\sim 80 \%$ ) of the scoriaceous clasts compared to the pumice. The static angle of repose, $\Theta_{s t}$, was estimated using ImageJ analysis of photographs and varied from 40 to $45^{\circ}$.

We also present a set of intrinsic parameters for the materials constrained from the literature. The internal friction coefficient, $\mu_{\text {int }}$ was estimated at 0.8 for the pumice samples and 0.6 for the VAL scoria, based on direct measurements [He and Senetakis 2019] and supported by experimental measurements of the angle of internal friction, $\alpha$ [Agustian and Goto 2008; Cagnoli 2004]. Given the similarities in shape and density, we assign the same $\mu_{i n t}$ values to LSB and 7C clasts. The coefficient of restitution, $e$, is estimated for pumice based on experimental observations by Mueller et al. [2015], who showed that the coefficient changes significantly with increasing particle smoothing and rounding, from $\sim 0.01$ for initial angular pumice particles to 0.7 for particles rounded by successive drop experiments (Table 3).

In summary, the results show that the LSB and 7C samples can be considered equivalent in terms of shape, density, and frictional properties. The VAL scoria material is slightly more angular, less rounded and more than twice as dense as the pumice samples. LSB clasts are better sorted than 7C and VAL clasts and have the smallest average diameter. 


\subsection{Production of ash}

Despite textural differences between the three samples (LSB, 7C and VAL), we observed consistent trends of ash generation accompanied by grain size reduction in all experiments for any starting sample weight, drum dimension or temperature. Ash generation, quantified as the percentage of $<2 \mathrm{~mm}$ particles generated after fixed time increments, is positively correlated with starting mass and is higher in type II experiments (ash removed at each time step) compared to type I experiments (ash and clasts put back in the drum at each time step). For pumice samples (LSB and 7C) the efficiency of ash generation was 7-12 wt. \% higher in type II experiments. Experiments in the small tumbling device did not fit into the mass-dependent trend observed in the cement mixer, however the time-dependent change in ash generation was comparable (Figure 3). The 7C clasts (Figure 3B) showed the highest ash generation efficiency (up to $\sim 53 \mathrm{wt}$. \% for type II experiment at $2 \mathrm{~kg}$ starting load), while LSB (Figure $3 \mathrm{~A}$ ) and VAL (Figure 3C) showed similar maximum ash production $\sim 36 \mathrm{wt} . \%$ and $\sim 38 \mathrm{wt}$. \%, respectively, for the same conditions. However, the scoria sample (VAL) showed a sharper fall in ash production with time than the pumice samples and generated up to $50 \%$ of the total ash in the first 15 minutes. VAL experiments also showed the greatest variability, which may be attributed to poorer sorting of the starting material (Table 3). Ash generation data are available in the online data repository [Hornby et al. 2020].

Based on our empirical data, we introduce a conceptual model of ash generation efficiency as a function of transport distance (Figure 4), derived for monomodal starting batches of angular clasts. The ash production rate is negatively correlated with transport distance and positively correlated with load. For all samples, distance-averaged ash production (wt. \% per $100 \mathrm{~m}$ ) was highest for the lowest distance measured, achieved in the small setup after 15 minutes. Whereas LSB and 7C show similar results (1.4 and 2.0, respectively), ash production for VAL was at least two times greater (4.0). However, the ash generation efficiency dropped most rapidly for VAL clasts, and at $>1 \mathrm{~km}$ tumbling distance the ash production rates for all experiments were similar to or lower than those of the pumice samples. This reflects an initially efficient abrasion which decreases with time or distance.

\subsection{Size reduction and rounding of clasts}

Particles became increasingly rounded and smooth during tumbling. We use the solidity (i.e. degree to which the shape of the particle is convex) and the form factor (a measure of the particle circularity) to characterise the evolution of shape during tumbling (Figure 5). We observe increases in both shape factors with experiment duration that broadly match the trends described in ash

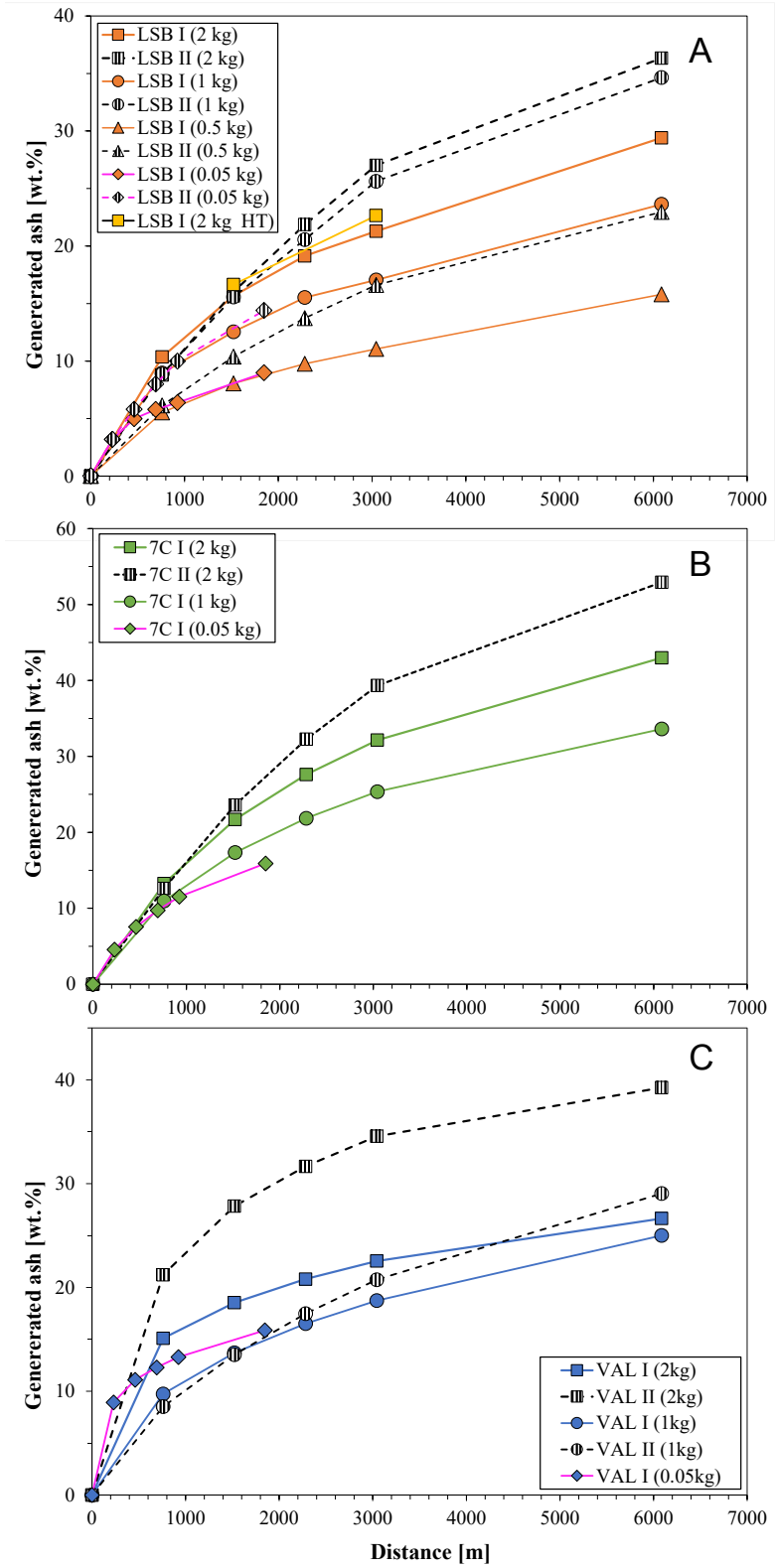

Figure 3: Ash production during tumbling experiments. Cumulative generation of ash $(<2 \mathrm{~mm}$ diameter) is plotted as wt.\% of the starting mass with rotational distance for all experiments using samples from [A] Laacher See (LSB), [B] Sete Cidades (7C) and [C] Valentano (VAL). Solid symbols, solid lines: type I experiments; black striped symbols, dashed lines: type II experiments; yellow lines and symbols: high temperature data for LSB; diamond symbols, pink lines: $0.05 \mathrm{~kg}$ experiments, conducted in the small tumbler. As all experiments lasted $2 \mathrm{~h}, 0.05 \mathrm{~kg}$ experiments had lower total tumbling distance. Type I and II experiments show substantial differences for LSB and 7C, with an almost linear decrease in ash generation efficiency in the latter, consistent with an energy dissipating effect of interclast ash in the bed. After $50 \%$ transport distance, ash production was 2-3 times higher in all type II experiments compared to corresponding type I experiments. 
Table 4 - Shape, size, and density of post-experimental samples for 120 -minute experiments with $2 \mathrm{~kg}$ starting load. Calliper measurements, mass, density and shape factors for large clasts following tumbling experiments with $2 \mathrm{~kg}$ starting mass and 120 minutes duration. Porosity $(\phi)$ is calculated using the average volume, $\mathrm{M}_{d}$, bulk density $\left(\rho_{b}\right)$ and pore-free density $\left(\rho_{s}\right)$. The volume $\left(\mathrm{V}_{f}\right)$ of $1 \mathrm{~kg}$ of sample was calculated based on a solid packing fraction of 0.45 .

\begin{tabular}{rccccccccccccc}
\hline Sample & $x$ & $y$ & $z$ & \multicolumn{1}{c}{$d$} & $M_{d}$ & $\sigma$ & $m_{c}[\mathrm{~g}]$ & $\rho_{b}$ & $\rho_{s}$ & $\phi$ & $V_{f}$ of 1 kg & Flatness & Elongation \\
\hline LSB I 120 & 6.04 & 8.67 & 12.40 & 8.69 & 0.34 & 0.22 & 0.15 & 0.48 & 2.48 & 80.7 & 4672 & 0.49 & 0.70 \\
LSB II 120 & 6.30 & 8.90 & 12.23 & 8.83 & 0.36 & 0.19 & 0.16 & 0.55 & 2.47 & 77.6 & 4013 & 0.51 & 0.73 \\
7C I 120 & 7.61 & 10.11 & 13.53 & 10.62 & 0.63 & 0.34 & 0.37 & 0.46 & 2.46 & 81.2 & 4808 & 0.55 & 0.75 \\
7C II 120 & 8.18 & 11.15 & 14.06 & 10.73 & 0.65 & 0.39 & 0.33 & 0.50 & 2.46 & 79.6 & 4421 & 0.56 & 0.75 \\
VAL I 120 & 7.14 & 10.03 & 12.20 & 9.91 & 0.51 & 0.45 & 0.60 & 1.31 & 3.07 & 57.3 & 1696 & 0.58 & 0.79 \\
VAL II 120 & 6.40 & 8.42 & 11.40 & 8.59 & 0.33 & 0.34 & 0.61 & 1.18 & 2.83 & 58.4 & 1888 & 0.59 & 0.82 \\
\hline
\end{tabular}

production (Figure 5). The solidity of all samples increased by 0.01 to 0.02 in the first 15 minutes. Subsequent tumbling of pumice samples (LSB and 7C) indicates constant solidity values after 45 to 60 minutes, but the scoria sample (VAL) exhibited a continuing increase in solidity beyond this time. The form factor evolves more constantly for all samples, up to at least 60 minutes. The degree of variability in clast shapes decreases with tumbling time, as seen from the diminishing box lengths marking the interquartile range. Interestingly, final solidity and form factor values were often highest for $1 \mathrm{~kg}$ starting loads rather than $2 \mathrm{~kg}$ (Figure 5C). Experiments in the small drum always had the lowest post-experimental shape factors. Type II experiments result in higher shape factor values than type I experiments together with increased ash production, indicating correlation between rounding and fines generation. The high temperature LSB experiments follow the same pattern as at room temperature.

After 120 minutes of tumbling, clasts were smaller and more rounded than the starting material. Detailed three-axis volume measurements show clast diameters reduced by $30-40 \%$ (Table 4 ). With the exception of $7 \mathrm{C} \mathrm{II}$, these values agree well with estimates from $2 \mathrm{D}$ image analysis and correspond to approximately $60 \%$ mass reduction. This overestimates the ash produced in the experiments by $10-20 \%$; however, we note that starting sample variability is not taken into account, while 2D image analysis indicates variations of $\sim 10 \%$ in average clast size between experiments on the same material. This is also reflected in variations in the bulk density shown in Table 4. Post-experimental clasts had become more sorted, with values of sorting decreasing by $9-18 \%$. In both cases, the greatest change in size and sorting was recorded for VAL clasts. For all samples, aspect ratios appear to be little affected by tumbling.

\subsection{Grain size distribution}

All experiments started with lapilli $(>4 \mathrm{~mm})$ clasts and no ash. As fine ash production was the most prominent process (disruptive events were rare), grain size analysis was restricted to separating and quantifying the amount of ash $(<2 \mathrm{~mm})$. Figure 6A shows sieving results for the ash from 120-minute tumbling experiments with $2 \mathrm{~kg}$ starting mass, showing that grain sizes are dominated by fine ash $(<3 \Phi)$ in all cases, with the VAL ash fraction slightly coarser than 7C and LSB. LSB type II ash shows a clear secondary peak at $1-2 \Phi$, while LSB type I ash has a coarse tail extending to 1-2Ф without such a secondary peak. Neither 7C nor VAL ash shows a similar coarse distribution. We further explore these coarse-grained features in the LSB ash in Figure 6B, showing variations with distance for $2 \mathrm{~kg}$ LSB type II experiments and comparing to type I experiments. We observe that the secondary peak in type II experiments is constrained to $1.5-2 \Phi$. The secondary peak height increases incrementally for each 15-minute step between 15 to 60 minutes, before decreasing in the final 60-minute step. In contrast, the type I experiment shows a lower peak at $1.5-2 \Phi$ and similar-sized peaks at the finer $2-2.5$ and $2.5-3 \Phi$ intervals, giving rise to a coarse-tailed rather than a bimodal distribution. To reveal characteristics in these dominantly fine-grained $<3 \Phi$ distributions, we present laser particle analysis data from 2-10Ф in Figure 6C. The curves show skewing toward finer grain sizes with tumbling duration for all samples, with the greatest change with for VAL fines. For LSB and 7C type II samples the mode and the peak shape remains almost constant between 15 to 60 minutes of tumbling; however, type I experiments and 120-minute type II experiments show slight depletions in the coarse tail of the peak. After 15 minutes of tumbling, the VAL fine ash has a relatively sharp, fine skewed peak with a mode at $90 \mu \mathrm{m}$ (3.5Ф). Between 30-60 minutes the peak broadens and the mode decreases to $63 \mu \mathrm{m}(4 \Phi)$ and after 120 minutes the peak decreases again to $32-45 \mu \mathrm{m}(3-3.5 \Phi)$ and the greatest fraction of $\mathrm{nm}$-sized particles is produced of all experiments. Little difference in the ash size reduction trend is observed between type I and type II samples for LSB and 7C loads, however the VAL II experiment shows significantly greater size reduction than the VAL I experiment: at 120 minutes the type I experiment has a similar grain size distribution to the type II experiment after only 30 minutes (Figure 6C). 

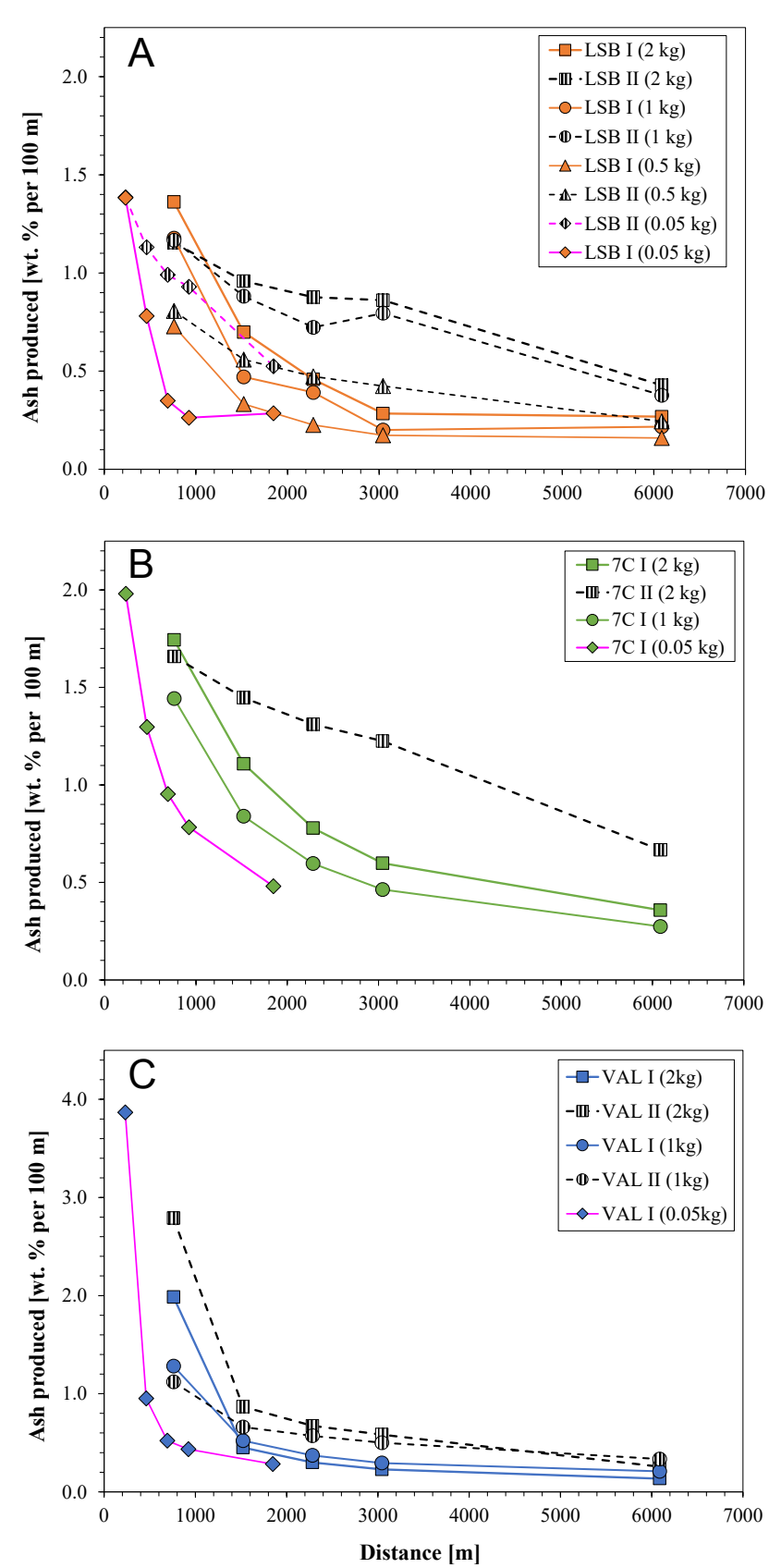

Figure 4: Change in rate of ash production during tumbling experiments. The evolution of ash production rate with increasing tumbling distance is shown for [A] Laacher See pumice (LSB); [B] Sete Cidades pumice $(7 \mathrm{C})$ and $[\mathrm{C}]$ Valentano scoria. Symbols, lines and colours are the same as for Figure 3. The data are plotted for each tumbling segment as the average weight fraction of ash produced per $100 \mathrm{~m}$ rotational distance in that segment. The mass was measured at the start and end of each experimental segment for each experimental protocol (type I and II, indicated by line dashes while symbols and line thickness identify the initial mass of the starting material).

\section{DiscusSION AND INTERPRETATION}

Characterising ash generation and clast attrition within pyroclastic density currents is important for two reasons: 1 ) ash production changes the grain size distribution in the flow, which affects the rheology, mass distribution, sedimentation rate, permeability and internal pressurisation of PDCs [Bursik and Woods 1996; Caballero et al. 2014; Dellino et al. 2010; Roche 2012]. Therefore, insights into the ash fraction produced within flow can help to predict potential affected areas and to develop hazard mapping; 2) ash produced in PDCs is often finer-grained and contains more groundmass glass than ash generated by magmatic fragmentation, leading to increased health and environmental hazards [Horwell et al. 2001; Horwell and Baxter 2006]. Here, we investigate the role of experimental and material parameters on the production of ash in tumbling apparatuses and the shape evolution of the abrading clasts under abrasion-dominated regimes with varying collisional energy input (Table 2).

The motion of particles in a rotary tumblerdependent on the rotational velocity, the drum diameter, the filling fraction, and the properties of the bedload-varies from slipping and rolling to cascading and cataracting with increasing rotation velocity. The bulk movement of particles in the upper (surface) layer of the bedload is in the opposite direction to particles transported by frictional plug flow in the lower layer of the bed. The mass flow rates in the upper and lower bedload layers are equivalent. With greater filling fraction and bed thickness, relative velocity approaches zero in the core of the bed, just below the flowing surface layer. In the lower bed, particle interactions are frictional and compressive, and ash is dominantly produced by abrasion, although force chains can impart substantial stresses [Estep and Dufek 2013]. Wider ranges of impact energy and relative velocity are observed for collisions in the upper layer, due to cascading, rolling, and saltation of particles. These clast-clast interactions lead to particle production via 1) abrasive wear of frictional contacts, 2) chipping during lowenergy collisions, and 3) splitting via high-energy collisions. Abrasion produces finer ash $(>3 \Phi)$ while increasing the solidity and form factor of the parent particle, which reduces the potential for subsequent ash generation by smoothing asperities. Chipping increases shape factors and produces coarser ash fragments $(<3 \Phi)$ that may be subsequently milled in the basal layer, while splitting decreases shape factors but produces new angular daughter particles that may be a relatively rich source of fine ash.

In the experiments presented here, dry volcanic clasts have been investigated for the generation of fine particles due to clast-clast collisions during tumbling experiments. The sample textures, starting load, and clast morphometrics influence 1) the cumulative weight of ash after each time step up to 120 minutes, 

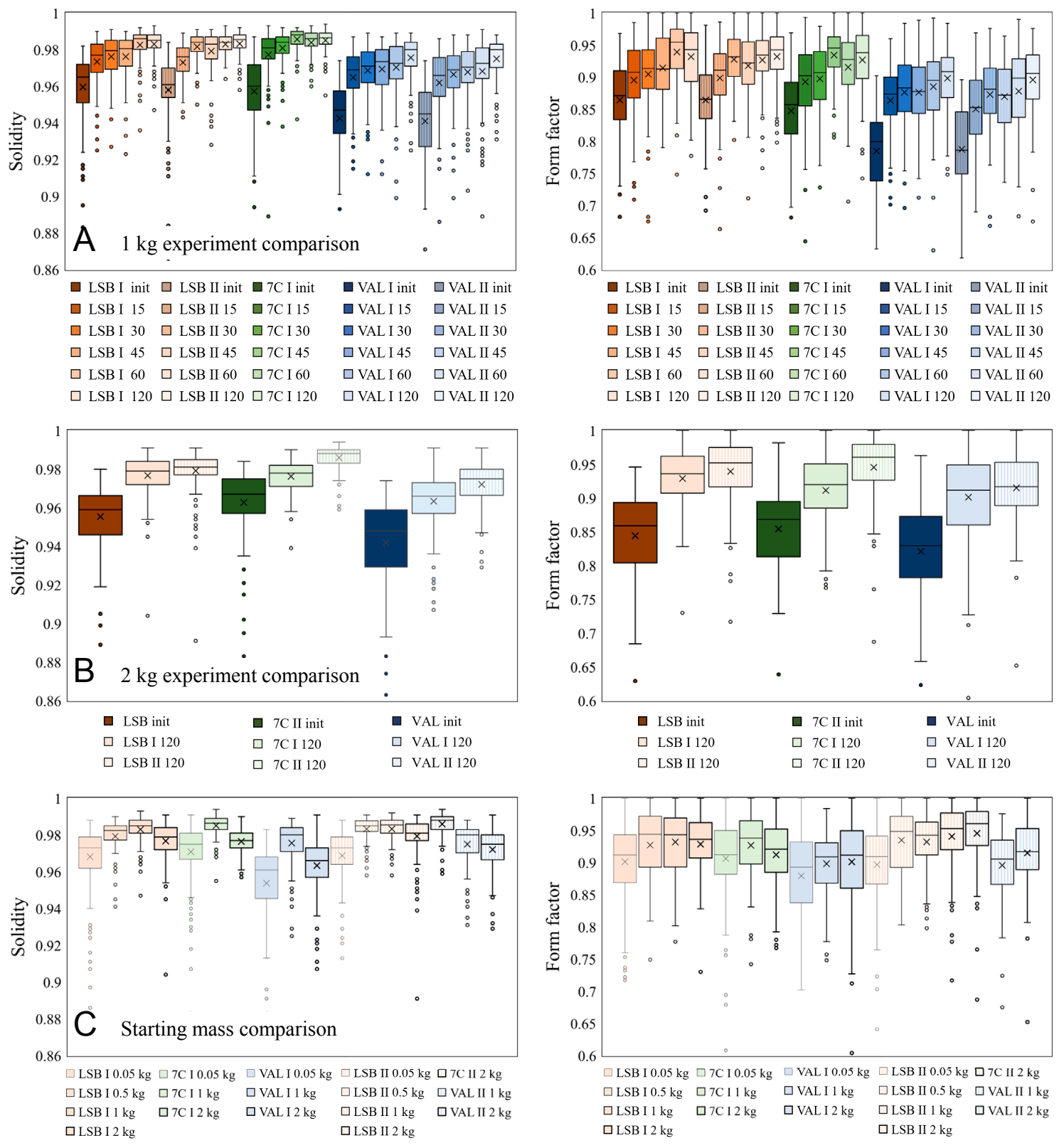

Figure 5: Shape evolution of clasts as function of experimental conditions. Box plots showing the distribution of solidity (left-hand panels) and form factor (right-hand panels). Shape factors for clasts tumbled for increasing tumbling duration are shown in progressively lighter shades (trailing numbers in the legend refer to the tumbling duration in minutes, and 'init' is the initial material). Type I and II experiments are shown as solid and striped boxes, respectively. The $25-75 \%$ range of the data is shown in the coloured boxes, the median is marked with a horizontal line and the mean is indicated by a cross. The whiskers extend up to 1.5 times the box range. Data falling outside this range are possible outliers and shown as coloured dots. [A] Data for multi-step experiments with $1 \mathrm{~kg}$ starting weight. For all five sample sets, the change in the shape factors is highest between initial material and clasts after 15 minutes tumbling. Pumice samples (LSB, 7C) achieve maximum values after 30 to 60 minutes of tumbling, indicating a high propensity for abrasion. Scoria samples (VAL) show linear changes between 15 and 120 minutes, indicating continued rounding at quasi-constant rates. [B] Shape characteristics of starting material and final clasts after 120-minute experiments with $2 \mathrm{~kg}$ starting weight. All samples (apparently minor for LSB) exhibit enhanced shape changes when ash is left out after each time interval. [C] Shape factors of LSB clasts following 120 minutes of tumbling with varying starting weights are plotted. The effect of static load at the drum base and the number of simultaneous clast-clast rotations is apparent. 
2) the GSD of the ash, and 3) the final shape of the clasts. In $2 \mathrm{~kg}$ runs, up to 3,300 particles were tumbled. The rare occurrence of flattened clasts in tumbled samples suggests that repetitive sliding and clast-drum friction played a subsidiary role in particle shaping compared to clast-clast interactions; however, interactions between clasts and the drum wall at the lower end of the bed surface must be considered. These are potentially the highest-energy interactions in the experimental system, but we note that gravitational acceleration is compensated by abrasion and chipping during rolling and saltation of the clasts in the flowing layer before clasts make contact with the drum wall at the end of the slope. Although these wall effects complicate particle interactions in the system, they should remain similar across our fixed-velocity experiments, where clast mass $(0.15-0.61 \mathrm{~g})$ and fill fraction $(3-10 \%)$ lie in a relatively narrow range. Relative clast motions during tumbling are affected by the change in drum geometry, fill fraction and drum wall material for the small

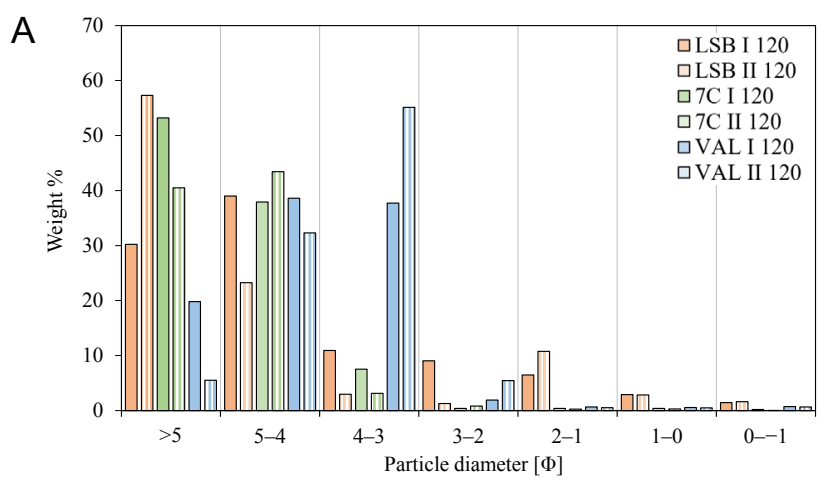

B
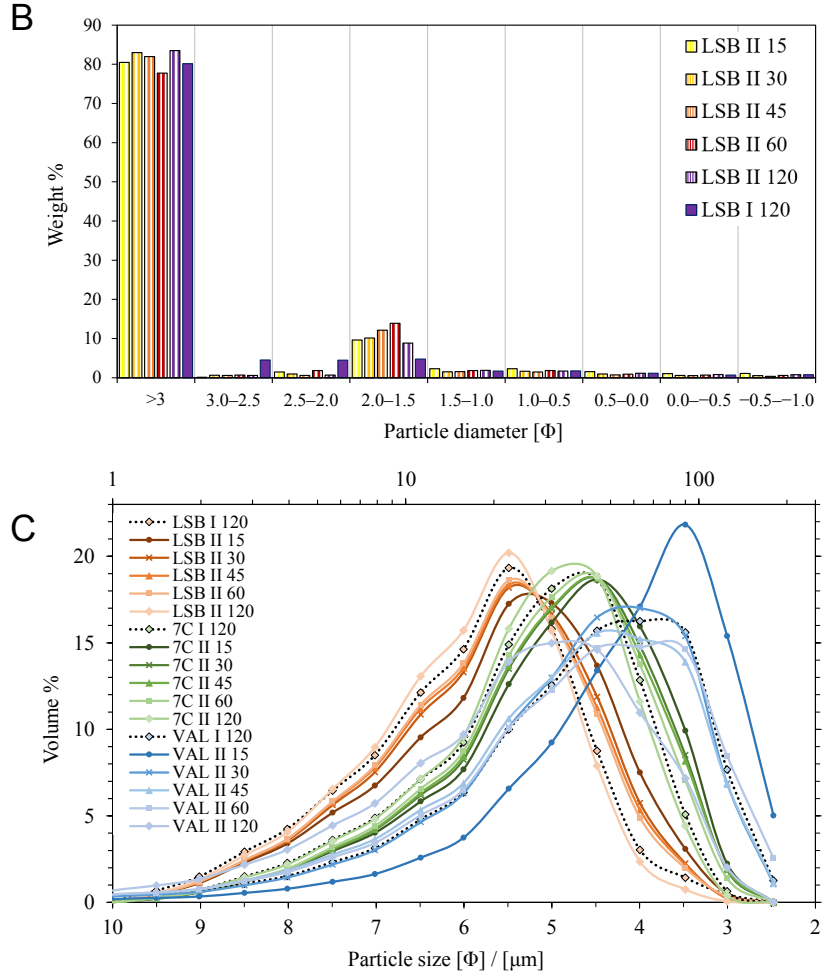

tumbler; however data for $0.05,0.5$, and $1 \mathrm{~kg}$ starting sample mass, respectively, show consistently reduced and lagged ash generation, therefore we conclude that the governing processes for ash generation do not vary significantly between the setups. The degree to which clast-wall impacts affect ash generation can be constrained in future studies by lining the drum interior with a shock-absorbing material. On the other hand, high-energy interactions with the substrate and lithic clasts may be common in the dense basal layer of PDCs [Caballero et al. 2012; Palladino and Giordano 2019], and future experiments incorporating high-energy interactions (e.g. including relatively large, dense clasts) may also provide further insight into ash production in natural systems.

The grain size distribution data (Figure 6) shows that LSB II samples show a secondary peak at 250$355 \mu \mathrm{m}(2-1 \Phi)$, while negligible mass fractions are measured between 125-250 $\mu \mathrm{m}(3-2 \Phi)$. Particles in the 2-1Ф range also have a speckled appearance, containing many more dark grains than in all finer or coarser size fractions. These visual observations and grain size properties suggest that mafic microlites in the $2-1 \Phi$ range are liberated during abrasion and that the free

Figure 6: Ash size distributions produced in tumbling experiments. [A] Results from dry sieving between 32 and $2000 \mu \mathrm{m}$ for all $2 \mathrm{~kg}$ starting mass experiments after 120 minutes of tumbling. LSB samples are shown in orange, 7C in green and VAL in blue. In all cases solid and striped bars denote type I and type II experiments, respectively. Note that LSB samples show enrichments in coarse $(1-3 \Phi)$ fractions. [B] Variations in the $<3 \Phi$ fractions for LSB $2 \mathrm{~kg}$ experiments are highlighted by half- $\Phi$ sieving. We note a clear secondary peak at 1.5$2 \Phi$ for type II experiments, while type I experiments show a coarse tail without a secondary peak extending from 3-1.5Ф. Colours differentiate experiment time steps, and bar shading follows that in panel [A]. [C] Laser particle size analysis reveals variations in fine ash fractions between samples, experiment types and duration. Fine skewing of the distributions occurs with longer tumbling in all cases. Colours denote samples using the same scheme as panel [A]; solid line are used for type II experiments and dotted black lines show a type I 120 minute experiment for each sample. For 7C and LSB type II samples, the mode remains almost constant with tumbling duration, while for VAL II samples it decreases from 3.5 to $5 \Phi(90$ to $40 \mu \mathrm{m})$. Note that LSB samples were pre-sieved to $<125 \mu \mathrm{m}(>3 \Phi)$ while VAL and $7 \mathrm{C}$ are bulk samples, and that relative variations in the laser particle sizer results are not concordant with sieving data in panel [A]. We attribute these discrepancies to small variations in sample humidity leading to fine particle aggregation and defer to the laser particle sizer results for grain sizes $<3 \Phi$. 
crystals are resistant to size reduction via chipping or abrasion. Neither the nominally aphyric 7C [Kueppers et al. 2019] nor the crystal-poor VAL ash [Perugini et al. 2011] show a similar secondary peak (although the coarser GSD of VAL ash may mask a secondary peak). A detailed examination of the LSB samples in Figure 6B suggests that there could be a significant role of the fine ash in fracturing free crystals. We note that when ash is removed at 15-minute intervals, increasing tumbling time or distance increases the height of the secondary peak in the 250-355 $\mu \mathrm{m}(2-1 \Phi)$ range in Figure 6B. On the other hand, the LSB I experiment, where ash is left in the tumbler, and the final 60 minute time step for LSB II, show a decrease in the 250-355 $\mu \mathrm{m}(2-1 \Phi)$ secondary peak, suggesting that crystals were more effectively fractured to finer grain sizes when ash was retained in the tumbler. This inferred splitting of crystals is most apparent for the LSB I experiment, where the secondary peak is broadened down to $125 \mu \mathrm{m}$. Fine ash production has been shown to increase viscosity and shear stress within wet debris flows and preferentially split intermediate-sized particles [Caballero et al. 2012; Caballero et al. 2014]. Our data suggests that intermediate-sized particles are also preferentially fractured in dry granular flows if fine ash can accumulate in the bedload.

We compare the rate of ash production in experiments by dividing the ash mass at each step distance by the (rotational) distance of the drum. Ash is produced both in the surface and base layer of the bedload, yet an equivalent flow distance of the bedload cannot be defined in the experiments, and therefore we use the drum rotation as a proxy. The average ash mass fraction produced per metre distance is calculated at each step and plotted for all starting loads, materials and apparatuses in Figure 4. The data show that the ash production rate decreases with tumbling distance for all experiments, but we observe different trends for type I and type II experiments with distance. This is most obvious in the pumice experiments (Figure 4A-B) where ash production rate diminished at a constant gradient for type II experiments, while type I experiments show a nonlinear decrease, from steeper gradients over the first $\sim 2000 \mathrm{~m}$, evolving to shallower gradients in the final steps. These trends indicate that the ash fraction within the bedload has an important damping effect on ash generation during tumbling, creating a power-law decrease in ash production efficiency when all ash produced is preserved in the tumbling load. On the other hand, the approximately linear decrease in ash production rate for the type II experiments shows that other factors govern the ash production efficiency via simple relationships. These factors likely include bed thickness, particle shape and particle size. Ash production rate is lower for any distance when the starting mass is lower; we observe smaller variation between 1 and $2 \mathrm{~kg}$ experiments than between 0.5 and $1 \mathrm{~kg}$ experiments. Data for the VAL material (Figure 4C) show nonlinear reductions in ash production efficiency with distance for both type I and type II experiments. Type II experiments are slightly more efficient, but the curves are similar for all experiments with VAL scoria. The small tumbler provided data points at the smallest distances and showed similar trends to the large tumbler.

Ash entrapment and removal occur in natural PDCs, via elutriation, deposition or flow pressurisation. We note that type I and type II experiments represent endmember scenarios, and natural flows will fall between full ash loss or retainment. In order to account for the effect of varying fractions of ash removal from a flow and to scale experiments with bed and clast dimensions, we propose a scaling of the tumbling distance by $h \xi S /\left(0.5 \pi d^{2}\right)$ in 2 dimensions or $h^{2} \xi S /\left(\frac{2}{3} \pi d^{3}\right)$ in 3 dimensions, where $\xi$ is a correction factor for ash loss from the flow. We calculate $\xi$ as the ash fraction removed/cumulative ash fraction produced in our multistep experiments. The scaling relates the clast dimensions to the flow dimensions and is reasonably successful at collapsing the ash production data onto a single curve (Figure 7). In the two-dimensional case, the clast projected area is compared to the longitudinal cross-section along a flow of length $S$, which produces a power-law regression for all data points, including the small tumbler. The best fit for the regression leads to

$$
\text { Ash produced }\left(\text { wt. \%) }=0.06\left(\frac{h \xi S}{0.5 \pi d^{2}}\right)^{0.37}\right.
$$

with a coefficient of determination $\left(R^{2}\right)$ of 0.77 . In the three-dimensional case, the clast volume is compared to flow volume for a nominally equant flow cross section. This greatly reduces scatter within for each material, however curves do not necessarily overlap, and large and small tumbler data fit on separate curves.

This scaling allows the ash produced by tumbling in a flow to be estimated from the principal dimensions; however, determining these dimensions from field deposits or observational evidence remains a significant challenge. In experiments, sample mass is fully retained within the system during any time step. In contrast, what is deposited directly from PDCs reflects flow conditions (velocity, temperature, turbidity, density etc), which vary widely in time and space. In many cases, a significant portion of the fines is typically absent, due to continued transport in an overriding dilute current or lofting by elutriation [Engwell and Eychenne 2016; Marti et al. 2016; Sparks and Walker 1977]. Therefore, the interpretation of grain size distribution and fines content in PDC deposits requires careful assessment of local flow conditions and deposit characteristics in addition to transport distance; interpretations are subject to significant uncertainty if direct PDC deposits are considered alone. However, analysis of lapilli shapes in PDC deposits at a known distance from the vent may be more likely to be representative transport distance, under the assumption that the probability of 

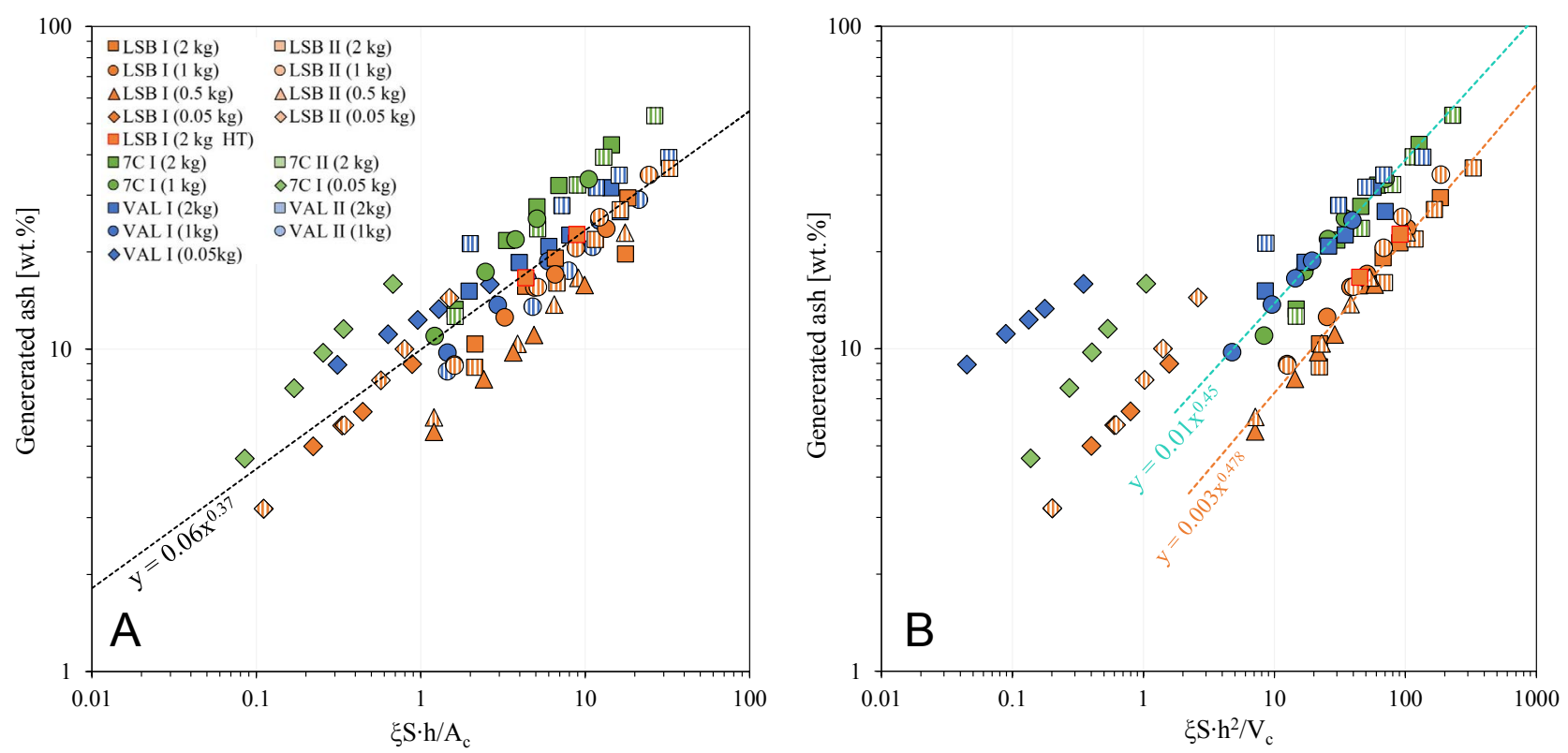

Figure 7: Ash production scaled by the flow and clast dimensions and corrected for ash removal. [A] Twodimensional scaling of the longitudinal cross section of the flow with the average projected area of the clasts collapses all data around a power-law curve, with a coefficient of determination $\left(R^{2}\right)$ of 0.77 . [B] Three-dimensional scaling of the flow volume (estimated from $h^{2} \times S$ ) with the average clast volume collapses data for the same starting material and the same apparatus onto a curve with $R^{2}>0.9$. However, LSB experiments do not overlap with 7C and VAL data, and the small tumbler data do not correlate. Linear regressions are shown in both panels by dashed and labelled lines. The key in [A] applies to both panels.

clast interactions increases with transport distance regardless of the final deposition conditions. Unfortunately, the few detailed studies of clast shapes in PDC deposits [Davies et al. 1978; Manga et al. 2011] have not revealed clear trends in roundness or sphericity (although initial to final variations are found). This may be due to a greater contribution from clast-disrupting events that partially 'reset' increases in roundness, particularly on steeper slopes [Andrews and Manga 2011; Manga et al. 2011]. Shape factors that incorporate the smoothness of particle shapes, e.g. solidity or defect area, may retain more signal from abrasive ash production following clast disruption, and should be evaluated from PDC deposits directly in the field either via image analysis or direct sampling. Here, we investigate relationships between ash production and clast shape evolution. Within our experiments we can assume an equivalence between the ash fraction produced and the average fractional volume loss of the clasts. The clast volume change with PDC flow distance may also be difficult to assess in nature, however this study shows that the volume reduction and ash produced can also be estimated as a function of the average solidity or circularity (Figure 8A).

All materials showed a similar evolution of clast shape with ash production, although the VAL clasts were consistently offset to lower shape factors. In the field, measurements of clast shape should be less sen- sitive than clast volume to temporal variations in flow transport energy, better reflecting the average flow conditions. With sufficient data to obtain an average clast shape factor at multiple distances from the source, and under the assumption that clasts were entrained the full length of the flow between the deposits, the ash fraction produced by abrasion can be approximated by taking the difference in shape factor. For the most numerous LSB experiments, ash produced can be calculated from $3 \times \delta$ Solidity $^{2}$ with $R^{2}$ of $\sim 0.7$, while VAL samples follow $2 \times \delta$ Solidity ${ }^{2.1}$ with $R^{2}$ of $\sim 0.85$. The deviation in the results indicates that sample numbers of $n>100$ clasts (as used here) are required for an accurate approximation of the gradient between two data points, however the bulk of the data describe a similar gradient for all experiment sets in Figure 8. Variations observed in ash production between type I and type II experiments (Figures 3 and 4) can be better evaluated by assessing the type of clast interactions within the drum during tumbling. In rotary tumblers, an estimate the bed behaviour and the nature of particle-particle interactions can be obtained via the Froude number, $F r=\omega \sqrt{D / 2 g}$, where $\omega$ is the angular velocity $(2 \pi / T$, where $T$ is the rotation period), which defines the ratio of centrifugal force to gravity $(g)$. The Froude number $(F r)$ of the experiments (the ratio of centrifugal to gravitational force) is 0.45 for the large tumbler and 0.37 for the small tumbling apparatus. Under no wall- 

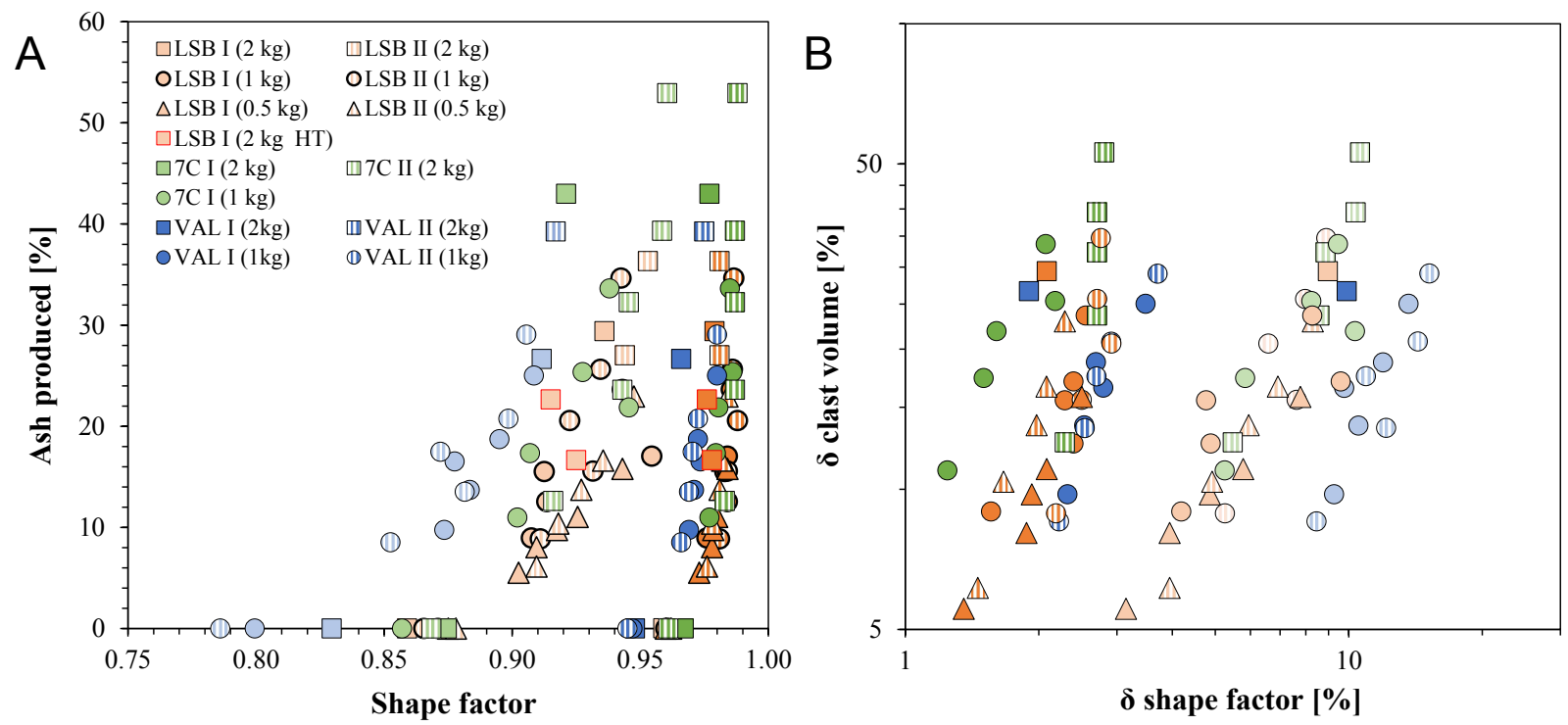

Figure 8: Solidity (dark colours) and form factor (pale colours) evolution with ash production. [A] A similar curve is observed for ash production and shape evolution during tumbling for all materials and starting masses, with VAL clasts offset to less circular and convex shapes than the pumice samples. Consistent variation between type I and type II experiments is not evident. [B] Fractional volume loss is equivalent to fractional ash production in a closed system; ash production shows a power law trend with change in solidity or form factor from an initial value. The key in $[\mathrm{A}]$ applies to both panels.

slip conditions and for filling fractions greater than 0.1 , when $0.01<F r<1$, where our experiments lie, the bed surface becomes oversteepened and particles cascade and cataract from the upper surface of the bed, colliding with particles lower in the bed and rolling down the bed surface [Mellmann 2001]. For low Fr, the bed shows rolling, sliding, and slumping regimes, while for $F r>1$ the bed centrifuges around the outside of the drum. Video imagery shows that the extent of wall slip increases with ash production in the experiments, and that low fill fractions in the large tumbler ( 0.016 to $0.06 \%$ for 0.5 to $2 \mathrm{~kg}$ experiments) cause rolling and cascading to dominate cataracting motions even for high $F r$.

In summary, collision energies are controlled by 1) the weight of individual clasts, 2) the rotational velocity, 3) the thickness of the flowing and cascading layer, and 4) and the relative ash fraction. The dynamic angle of repose and the thickness of the flowing layer $h_{f}$ are required to better quantify the collisional energy in the surface layer.

In the absence of direct observation of particle interactions and bed behaviour, we adopt a set of empirical relations with flow rate [Chou and Lee 2009; GDR MiDi 2004] using data from tests over a wide range of fill fractions and $F r$. Although our experimental setup varies from these studies, the underpinning flow rate constraints during tumbling remain valid. Past studies [Chou and Lee 2009; GDR MiDi 2004] have noted that with increasing $\mathrm{Fr}$ and decreasing bed thickness, $h_{f}$ converges toward $0.5 h$. For other experiments, a dimensionless flow parameter $Q^{*}$ can be used to scale the thickness of the flowing layer and the dynamic angle of repose. The flow rate $Q$ is calculated from the filling fraction $f$ and the cycle time in the bed under no-slip conditions. For a half-filled drum, $Q=\omega D^{2} / 8$; for lower fill fractions, substitutions for the filling angle $\Theta_{f}$, and $\operatorname{Fr}$ (Equation 1) result in $Q=\left(\omega D^{2} / 8\right)(1-$ $[\sin \Theta f / \Theta f])$. Finally, the flow rate is normalised by $h \sqrt{g d}$ allowing scaling either to the clast diameter or the bed height [Chou and Lee 2009], yielding

$$
Q^{*} \propto \frac{Q}{h \sqrt{g d}}
$$

and

$$
Q^{*}=\kappa \cdot F r \sqrt{\frac{D}{d}} \cdot \frac{1-\sin 2 \Theta_{f} / 2 \Theta_{f}}{1-\cos \left(\Theta_{f}\right)}
$$

where $\kappa$ is a constant and $h=D(1-[\cos \Theta f / 2])$. Once $Q^{*}$ is calculated, both $\Theta_{d y n}$ and $h_{f}$ can be estimated as functions of $\sqrt{Q^{*}}$, using $\Theta_{d y n} / \Theta=0.185 \sqrt{Q^{*}}+1$ and $h_{f} / f \approx 0.25 \sqrt{Q^{*}}$ These empirical relations are obtained from linear regressions for slipping experiments on a smooth wall surface from data presented in Chou and Lee [2009]. Those authors also present data for the velocity of the surface layer relative to the basal layer, from which the linear regression $u_{s} / u_{b} \approx-1.8 \sqrt{Q^{*}}+4.1$ can be derived from data for high $F r$ and low $f$ experiments. We calculate $Q^{*}$ independently using Equations 1 and 2 and constrain the value of $\kappa$ to 0.354 in all experiments. 

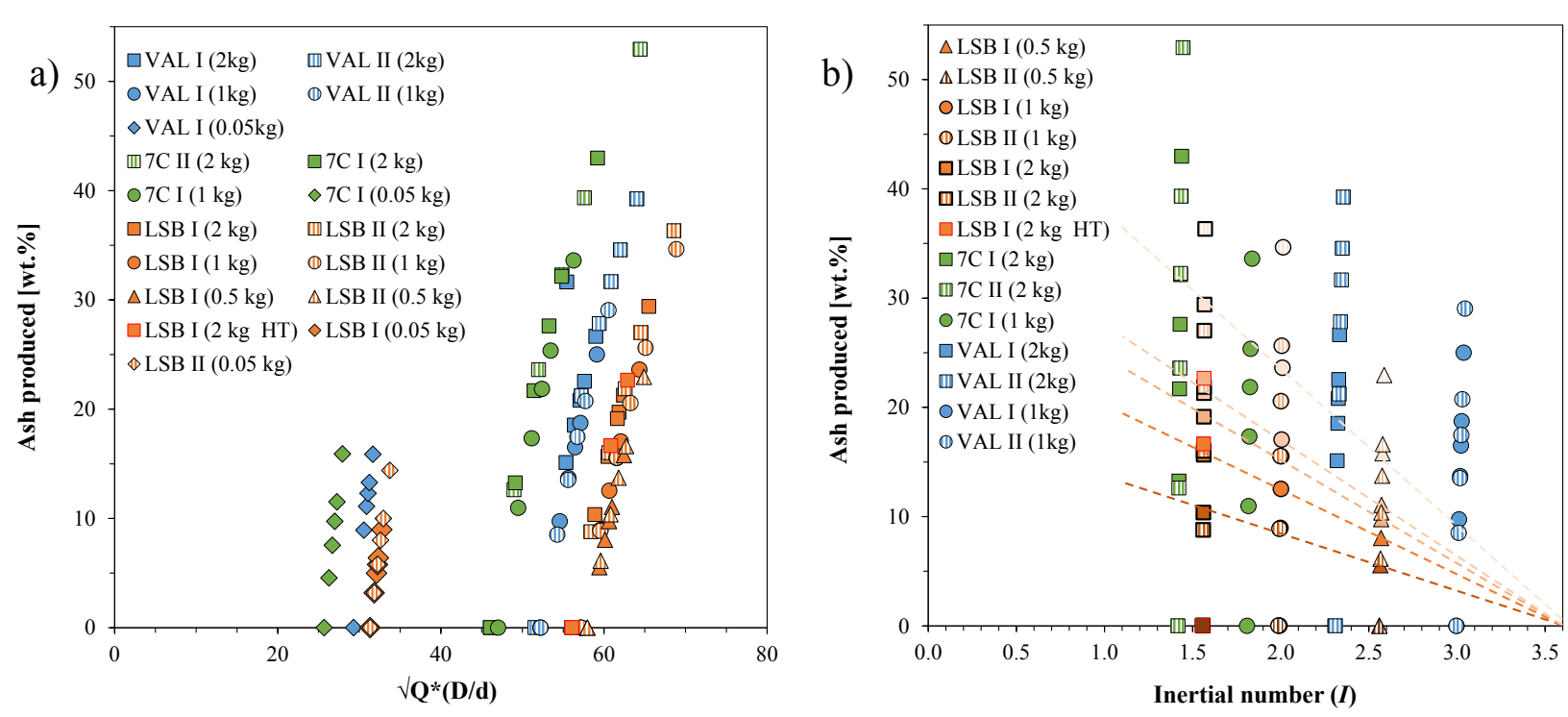

Figure 9: [A] Ash produced as a function of normalised flow rate $\left(\sqrt{Q^{*}}(D / d)\right)$ varies with starting mass and material, while type I and II experiments collapse onto a curve. Experiments in the small tumbler show a different trend (see inset), but maintain the relationship between the different materials. [B] Ash production is plotted as a function of the non-dimensional inertial number, $I$. Values of $I$ increase with decreasing starting volume for a given material. Increasing tumbling distances are indicated with lighter coloured data points. For type I experiments of LSB, dashed lines are drawn between points at the same tumbling distance but with varying $I$ value. These lines converge on the $\mathrm{x}$-axis at at $I \approx 3.6$, indicating that ash produced is a function of $I$ and tumbling distance for these experiments.

During an experiment, normalised flow rate $\left(Q^{*}\right)$ values increase as both bed height and clast diameter decrease. Data for a single material and starting mass plot on the same curve for both experiment types, however lower starting mass increases $\sqrt{Q^{*}}$ and variations in material and apparatus also shift the curves (Figure 9A). Lower initial values of $\sqrt{Q^{*}}$ are associated with higher ash production for a given tumbling distance. VAL and LSB data overlap, while 7C data plot separately due to larger clast diameter for 7C. VAL clasts are also larger than LSB clasts, but this is mitigated by higher bulk density. Plotting $\sqrt{Q^{*}}(D / d)$ against percentage ash production resulted in a single curve for all experiments using the same material (Figure 9A). Since $\sqrt{D / d}$ is a factor in Equation 5, this suggests a flow rate scaling in our experiments of $D / d^{3 / 2}$. We use the empirical formula from Chou and Lee [2009] to derive the height of the flowing layer and the dynamic friction angle; from these we now estimate the shear rate via $\dot{\gamma}=\omega / h_{f}$. The effective friction coefficient of a flow can be calculated solely as a function of $I$ under certain constraints, and here we assess whether ash production can also be scaled with $I$. Using the obtained dynamic friction angle $\Theta$, calculation of the dimensionless inertial number $I$ [Jop et al. 2006], defined as $I=\dot{\gamma} d / \sqrt{P / \rho}$ can be simplified by substituting $P=\rho g d \cos \Theta$ to obtain:

$$
I=\dot{\gamma} \sqrt{d /(g \cos \Theta)} .
$$

Type I and II experiments plot on the same trend, while I decreases slightly during experiments. VAL experiments are offset to higher I values, due to their relatively high bulk density. The dashed lines in Figure 9B show that, for type I experiments of LSB, ash produced for different starting loads varies linearly with the inertial number at a given tumbling distance, with experiments at lower $I$ producing more ash. We also note that the gradient between ash produced at different starting loads increases with distance, converging on the $\mathrm{x}$ intercept at approximately $I=3.6$. This convergence offers the possibility to model the ash produced for any starting mass solely as a function of the inertial number and tumbling distance. We obtain the empirical function as below:

$$
\text { Ash produced }=(-4.1 \ln S+22.5) \cdot I+(15.3 \ln S+84)
$$

We note that a similar function appears to hold for type I experiments with 7C material, while type II experiments appear to exhibit more complex relationships. More data are required to better define the variation with rotation rate and starting mass, in addition to the dependence on constitutive material properties, however these initial results suggest that ash production and clast morphometrics can be well-described if knowledge of the fundamental flow dimensions or flow properties are constrained. Also, flow properties defined for ideal granular flows (e.g. flow rate) may be used to assess more complex abrading materials and 
drum configurations. Nevertheless, the role of material properties (i.e. hardness, surface roughness) and flow rate on the observed variations in ash production require further investigation.

\section{Conclusions}

Here, we have investigated the effect of sample texture (between pumice and scoria), starting load and ash removal on ash generation in rotary tumbling experiments using a modified cement mixer. The experiments produced up to $53 \mathrm{wt}$. \% fine ash over the course of two hours and up to $6 \mathrm{~km}$ tumbling distance. Natural PDCs are surely less homogeneous currents than our experiments and travel considerably faster (at least for some time). As such, our results indicate a lower, conservative estimation on ash generation processes during surface-parallel pyroclast transportation. We observe that 1 ) increased starting mass increases the ash fraction for a given distance; 2 ) ash production rate decreases rapidly when ash is left within the load; 3 ) more angular and less-sorted starting materials increase and maintain ash production rate; 4 ) the grain size of ash produced is fine (modes at $25-50 \mu \mathrm{m}$ for pumice (7C and LSB), and 35-90 microns for scoriaceous (VAL) samples and incrementally decreases with tumbling distance; 5) breakage of loose crystals is promoted by higher fine ash fractions in the experimental loads; and 6) clasts become more rounded and smooth-edged with increasing ash production. No change in behaviour is observed in experiments heated up to $130^{\circ} \mathrm{C}$ (although variations in elutriated ash are not simulated in our sealed experiments) and similar trends are found in a smaller rotary tumbler. We propose a simple correction factor for the ash removed and normalise all experimental ash production data by the load height and the average clast diameter to retrieve a single power law fitting for ash production under our range of experimental conditions (filling fractions 3-28\%, ash fully removed or fully retained, starting material density 0.48 $1.24 \mathrm{~g} \mathrm{~cm}^{-3}$ ).

We also find that ash production follows a power law function with both clast solidity and form factor, and show that the change in shape factor with flow distance can be used to estimate ash generation within a regime dominated by abrasion and chipping. Finally, we calculate flow rate normalised to the apparatus and clast dimensions. Using empirical relationships from published studies of granular flow dynamics in a rotating drum, the shear rate and dynamic angle of repose were estimated. From these, we calculate the inertial number $I$, and show that ash production with varying flow height can be accurately modelled for a single material with full ash retention as a function of the inertial number and the flow distance. Other scenarios may be more complex, and the role of constitutive parameters such as material hardness and surface roughness, as well as velocity and clast density variations should be considered in future studies.

\section{Acknowledgements}

We thank Kyoko Kataoka as handling editor as well as Benjamin Andrews and Martin Jutzler for their constructive review comments. AH acknowledges support from the EU Commission under Marie-Curie Actions grant AVAST 753900. BM and CP acknowledge the support from LMU funded STUDI_FORSCHT@GEO projects S18_F2 and W19_F2, respectively. UK acknowledges support from VERTIGO (Grant Agreement number 607905). DBD acknowledges the support of ERC 2018 ADG 834225 (EAVESDROP). Fabian Wadsworth is thanked for discussions on scaling and modelling. Leonhard Bendel is thanked for hosting our data retreat on the Rechelkopf in the Bavarian Alps.

\section{Author contributions}

$\mathrm{AH}$ and UK conceived the study and designed the experiments. $\mathrm{BM}, \mathrm{CP}, \mathrm{AH}$ and $\mathrm{UK}$ conducted rotary drum experiments and collected samples. UK made porosity measurements; UK and BM took calliper measurements. AH took GSD measurements, wrote macros and conducted image analysis. Experiments and measurements were supported by DBD. AH, BM and UK analysed ash production data. AH conducted clast morphometric analysis, scaling and flow analysis. All authors contributed to the manuscript.

\section{Data aVailability}

All data supporting the study will be published to an open access repository, conditional on acceptance of the manuscript, as: Hornby, AJ; Kueppers, U; Maurer, B; Poetsch, C; Dingwell, DB. (2020): Ash generation of volcanic lapilli during rotary tumbling. GFZ Data Services. http://doi .org/10.5880/fidgeo.2020.025

\section{COPYRIGHT NOTICE}

(c) The Author(s) 2020. This article is distributed under the terms of the Creative Commons Attribution 4.0 International License, which permits unrestricted use, distribution, and reproduction in any medium, provided you give appropriate credit to the original author(s) and the source, provide a link to the Creative Commons license, and indicate if changes were made.

\section{REFERENCES}

Agustian, Y. and S. Goto (2008). "Strength and Deformation Characteristics of Scoria in Triaxial Compres- 
sion at Low Confining Stress". Soils and Foundations 48.1, pp. 27-39. DoI: 10.3208/sandf. 48.27.

Andrews, B. J. and M. Manga (2011). "Effects of topography on pyroclastic density current runout and formation of coignimbrites". Geology 39.12, pp. 10991102. Dor: $10.1130 / \mathrm{g} 32226.1$.

Ayris, P. M. and P. Delmelle (2012). "The immediate environmental effects of tephra emission". Bulletin of Volcanology 74.9, pp. 1905-1936. DOI: 10.1007 / s00445-012-0654-5.

Bagheri, G. and C. Bonadonna (2016). "Aerodynamics of Volcanic Particles". Volcanic Ash. Elsevier, pp. 3952. DoI: $10.1016 / \mathrm{b} 978-0-08-100405-0.00005-7$.

Branney, M. J. and P. Kokelaar (2003). "Pyroclastic density currents and the sedimentation of ignimbrites". Geological Society of London. Dor: 10.1144/gsl .mem. 2003.027.

Breard, E. C. P., G. Lube, J. R. Jones, J. Dufek, S. J. Cronin, G. A. Valentine, and A. Moebis (2016). "Coupling of turbulent and non-turbulent flow regimes within pyroclastic density currents". Nature Geoscience 9.10, pp. 767-771. DOI: 10.1038/ngeo2794.

Brouwers, H. J. H. (2006). "Particle-size distribution and packing fraction of geometric random packings". Physical Review E 74.3. Dor: 10.1103/physreve.74. 031309.

Brown, S. K., S. F. Jenkins, R. S. J. Sparks, H. Odbert, and M. R. Auker (2017). "Volcanic fatalities database: analysis of volcanic threat with distance and victim classification". Journal of Applied Volcanology 6.1. DoI: 10.1186/s13617-017-0067-4.

Buckland, H. M., J. Eychenne, A. C. Rust, and K. V. Cashman (2018). "Relating the physical properties of volcanic rocks to the characteristics of ash generated by experimental abrasion". Journal of Volcanology and Geothermal Research 349, pp. 335-350. Dor: 10.1016/j. jvolgeores.2017.11.017.

Bursik, M. I. and A. W. Woods (1996). "The dynamics and thermodynamics of large ash flows". Bulletin of Volcanology 58.2-3, pp. 175-193. DOI: 10.1007 / s004450050134.

Caballero, L., D. Sarocchi, L. Borselli, and A. I. Cárdenas (2012). "Particle interaction inside debris flows: Evidence through experimental data and quantitative clast shape analysis". Journal of Volcanology and Geothermal Research 231-232, pp. 12-23. DoI: 10 . 1016/j . jvolgeores. 2012.04.007.

Caballero, L., D. Sarocchi, E. Soto, and L. Borselli (2014). "Rheological changes induced by clast fragmentation in debris flows". Journal of Geophysical Research: Earth Surface 119.9, pp. 1800-1817. Dor: 10 . $1002 / 2013 \mathrm{j} \mathrm{f} 002942$.

Cagnoli, B. (2004). "Granular mass flows and Coulomb's friction in shear cell experiments: Implications for geophysical flows". Journal of Geophysical Research 109.F4. DoI: 10.1029/2004jf000177.

Cagnoli, B. and G. P. Romano (2012). "Effects of flow volume and grain size on mobility of dry granular flows of angular rock fragments: A functional relationship of scaling parameters". Journal of Geophysical Research: Solid Earth 117.B2, n/a-n/a. DoI: 10 . 1029/2011jb008926.

Calder, E. S., P. D. Cole, W. B. Dade, T. H. Druitt, R. P. Hoblitt, H. E. Huppert, L. Ritchie, R. S. J. Sparks, and S. R. Young (1999). "Mobility of pyroclastic flows and surges at the Soufriere Hills Volcano, Montserrat". Geophysical Research Letters 26.5, pp. 537-540. DOI: $10.1029 / 1999 \mathrm{gl} 900051$.

Calder, E. S., R. S. J. Sparks, and M. Gardeweg (2000). "Erosion, transport and segregation of pumice and lithic clasts in pyroclastic flows inferred from ignimbrite at Lascar Volcano, Chile". Journal of Volcanology and Geothermal Research 104.1-4, pp. 201-235. Dor: $10.1016 / \mathrm{s} 0377-0273(00) 00207-9$.

Chou, H.-T. and C.-F. Lee (2009). "Cross-sectional and axial flow characteristics of dry granular material in rotating drums". Granular Matter 11.1, pp. 13-32. DOI: $10.1007 / \mathrm{s} 10035-008-0118-y$.

Cleary, P. W. and R. D. Morrison (2016). "Comminution mechanisms, particle shape evolution and collision energy partitioning in tumbling mills". Minerals Engineering 86, pp. 75-95. Dor: 10.1016/j.mineng . 2015.12.006.

Dartevelle, S., G. G. Ernst, J. Stix, and A. Bernard (2002). "Origin of the Mount Pinatubo climactic eruption cloud: Implications for volcanic hazards and atmospheric impacts". Geology 30.7, p. 663. Dor: 10.1130/0091-7613(2002) $030<0663$ : ootmpc>2 . 0. co ; 2.

Davies, D. K., M. W. Quearry, and S. B. Bonis (1978). "Glowing avalanches from the 1974 eruption of the volcano Fuego, Guatemala”. Geological Society of America Bulletin 89.3, p. 369. DOI: $10.1130 / 0016$ 7606(1978) 89<369: gafteo>2.0.co; 2 .

Delaney, G. W., J. E. Hilton, and P. W. Cleary (2011). "Defining random loose packing for nonspherical grains". Physical Review E 83.5. Dor: 10.1103/ physreve.83.051305.

Dellino, P., R. Büttner, F. Dioguardi, D. M. Doronzo, L. La Volpe, D. Mele, I. Sonder, R. Sulpizio, and B. Zimanowski (2010). "Experimental evidence links volcanic particle characteristics to pyroclastic flow hazard". Earth and Planetary Science Letters 295.1-2, pp. 314-320. DoI: 10.1016/j .eps1.2010.04.022.

Denlinger, R. P. (1987). "A model for generation of ash clouds by pyroclastic flows, with application to the 1980 eruptions at Mount St. Helens, Washington". Journal of Geophysical Research: Solid Earth 92.B10, pp. 10284-10298. DoI: 10.1029/jb092ib10p10284.

Douillet, G. A., É. Tsang-Hin-Sun, U. Kueppers, J. Letort, D. A. Pacheco, F. Goldstein, F. Von Aulock, Y. Lavallée, J. B. Hanson, J. Bustillos, C. Robin, P. Ramón, M. Hall, and D. B. Dingwell (2013). "Sedimentology and geomorphology of the deposits from the August 2006 pyroclastic density currents at Tungurahua volcano, Ecuador". Bulletin of Volcanology 75.11. DOI: $10.1007 / \mathrm{s} 00445-013-0765-7$. 
Elskamp, F., H. Kruggel-Emden, M. Hennig, and U. Teipel (2017). "A strategy to determine DEM parameters for spherical and non-spherical particles". Granular Matter 19.3. DoI: 10 . 1007 / s10035-017 0710- 0 .

Engwell, S. and J. Eychenne (2016). "Contribution of Fine Ash to the Atmosphere From Plumes Associated With Pyroclastic Density Currents". Volcanic Ash. Elsevier, pp. 67-85. DoI: 10.1016/b978-0-08-100405$\odot .00007-\odot$.

Estep, J. and J. Dufek (2013). "Discrete element simulations of bed force anomalies due to force chains in dense granular flows". Journal of Volcanology and Geothermal Research 254, pp. 108-117. DoI: 10.1016/ j. jvolgeores. 2012.12.023.

Evans, J. R., J. E. Huntoon, W. I. Rose, N. R. Varley, and J. A. Stevenson (2009). "Particle sizes of andesitic ash fallout from vertical eruptions and co-pyroclastic flow clouds, Volcán de Colima, Mexico". Geology 37.10, pp. 935-938. DoI: 10.1130/g30208a.1.

Fauria, K. E., M. Manga, and M. Chamberlain (2016). "Effect of particle entrainment on the runout of pyroclastic density currents". Journal of Geophysical Research: Solid Earth 121.9, pp. 6445-6461. DoI: 10 . $1002 / 2016 \mathrm{jb} \odot 13263$.

Félix, G., V. Falk, and U. D’Ortona (2007). “Granular flows in a rotating drum: the scaling law between velocity and thickness of the flow". The European Physical Journal E 22.1, pp. 25-31. Dor: 10.1140 / epje / e2007-00002-5.

Folk, R. L. (1966). "A review of grain-size parameters". Sedimentology 6.2, pp. 73-93. DoI: $10.1111 /$ j.13653091. 1966. tb01572.x.

Folk, R. L. and W. C. Ward (1957). "Brazos River bar [Texas]; a study in the significance of grain size parameters". Journal of Sedimentary Research 27.1, pp. 3-26. DoI: 10 . $1306 / 74 d 70646$ - 2b21 - 11d7 $8648000102 \mathrm{c} 1865 \mathrm{~d}$.

Forterre, Y. and O. Pouliquen (2008). "Flows of Dense Granular Media". Annual Review of Fluid Mechanics 40.1, pp. 1-24. DoI: $10.1146 /$ annurev . fluid. 40 . 111406.102142 .

Freundt, A. and H. Schmincke (1992). "Abrasion in pyroclastic flows". Geologische Rundschau 81.2, pp. 383-389. DoI: $10.1007 / \mathrm{bf01828605.}$

Govender, I. (2016). "Granular flows in rotating drums: A rheological perspective". Minerals Engineering 92, pp. 168-175. DoI: 10.1016/j.mineng.2016.03.021.

Gray, J. M. N. T. and B. P. Kokelaar (2010). "Large particle segregation, transport and accumulation in granular free-surface flows". Journal of Fluid Mechanics 652, pp. 105-137. Dor: 10.1017/s002211201000011x.

Groupement De Recherche Milieux Divisés [GDR MiDi] (2004). "On dense granular flows". The European Physical Journal E 14.4, pp. 341-365. Dor: 10. 1140/epje/i2003-10153- $\odot$.
Guimarães, L. F., A. J. Hornby, U. Kueppers, A. Alves, V. de Assis Janasi, and D. B. Dingwell (2019). "Generation of block-and-ash flows at the onset of silicic volcanism in the Paraná Magmatic Province (Brazil): evidence from photoanalysis of Caxias do Sul breccias". Bulletin of Volcanology 81.11. DOI: 10.1007 / s00445019-1332-7.

He, H. and K. Senetakis (2019). "An experimental study on the micromechanical behavior of pumice". Acta Geotechnica 14.6, pp. 1883-1904. DOI: 10.1007/ s11440-019-00867-x.

Hornby, A. J., U. Kueppers, B. Maurer, C. Poetsch, and D. B. Dingwell (2020). "Ash generation of volcanic lapilli during rotary tumbling". GFZ Data Services. DoI: $10.5880 /$ fidgeo.2020.025.

Hornby, A. J., Y. Lavallée, J. E. Kendrick, G. Rollinson, A. R. Butcher, S. Clesham, U. Kueppers, C. Cimarelli, and G. Chigna (2019). "Phase partitioning during fragmentation revealed by QEMSCAN Particle Mineralogical Analysis of volcanic ash". Scientific Reports 9.1. Dor: $10.1038 / \mathrm{s} 41598-018-36857-4$.

Horwell, C. J., L. P. Braña, R. S. J. Sparks, M. D. Murphy, and V. L. Hards (2001). "A geochemical investigation of fragmentation and physical fractionation in pyroclastic flows from the Soufrière Hills volcano, Montserrat". Journal of Volcanology and Geothermal Research 109.4, pp. 247-262. DoI: $10.1016 /$ s0377$0273(00) 00319-\mathrm{x}$.

Horwell, C. J. and P. J. Baxter (2006). "The respiratory health hazards of volcanic ash: a review for volcanic risk mitigation". Bulletin of Volcanology 69.1, pp. 124. DoI: $10.1007 / \mathrm{s} 00445-006-0052-y$.

Jones, T. J., K. McNamara, J. Eychenne, A. C. Rust, K. V. Cashman, B. Scheu, and R. Edwards (2016). "Primary and secondary fragmentation of crystalbearing intermediate magma". Journal of Volcanology and Geothermal Research 327, pp. 70-83. Dor: 10 . 1016/j. jvolgeores. 2016.06.022.

Jones, T. and K. BéruBé (2011). "The bioreactivity of the sub-10um component of volcanic ash: Soufriére Hills volcano, Montserrat". Journal of Hazardous Materials 194, pp. 128-134. Dor: 10.1016/j . jhazmat. 2011.07. 092.

Jop, P., Y. Forterre, and O. Pouliquen (2006). "A constitutive law for dense granular flows". Nature 441.7094, pp. 727-730. DoI: 10.1038 /nature 04801.

Kelfoun, K., P. Samaniego, P. Palacios, and D. Barba (2009). "Testing the suitability of frictional behaviour for pyroclastic flow simulation by comparison with a well-constrained eruption at Tungurahua volcano (Ecuador)". Bulletin of Volcanology 71.9, pp. 1057-1075. Dor: 10.1007/s00445-009-0286-6.

King, R. (2001). "Comminution operations". Modeling and Simulation of Mineral Processing Systems. Elsevier, pp. 127-212. Dor: 10.1016/b978-0-08-0511849.50009-2. 
Kueppers, U., A. Pimentel, B. Ellis, F. Forni, J. Neukampf, J. Pacheco, D. Perugini, and G. Queiroz (2019). "Biased Volcanic Hazard Assessment Due to Incomplete Eruption Records on Ocean Islands: An Example of Sete Cidades Volcano, Azores". Frontiers in Earth Science 7. DoI: 10.3389/feart.2019.00122.

Kueppers, U., C. Putz, O. Spieler, and D. B. Dingwell (2012). "Abrasion in pyroclastic density currents: Insights from tumbling experiments". Physics and Chemistry of the Earth, Parts A/B/C 45-46, pp. 33-39. Dor: $10.1016 / \mathrm{j}$.pce.2011.09.002.

Legland, D., I. Arganda-Carreras, and P. Andrey (2016). "MorphoLibJ: integrated library and plugins for mathematical morphology with ImageJ". Bioinformatics, btw413. DoI: 10.1093 / bioinformatics / btw413.

Lube, G., E. C. P. Breard, J. Jones, L. Fullard, J. Dufek, S. J. Cronin, and T. Wang (2019). "Generation of air lubrication within pyroclastic density currents". Nature Geoscience 12.5, pp. 381-386. Dor: 10.1038 / s41561-019-0338-2.

Macorps, E., S. J. Charbonnier, N. R. Varley, L. Capra, Z. Atlas, and J. Cabré (2018). "Stratigraphy, sedimentology and inferred flow dynamics from the July 2015 block-and-ash flow deposits at Volcán de Colima, Mexico". Journal of Volcanology and Geothermal Research 349, pp. 99-116. Dor: $10.1016 / \mathrm{j}$. jvolgeores.2017.09.025.

Manga, M., A. Patel, and J. Dufek (2011). "Rounding of pumice clasts during transport: field measurements and laboratory studies". Bulletin of Volcanology 73.3, pp. 321-333. DoI: $10.1007 / \mathrm{s} 00445-010-0411-6$.

Marti, A., A. Folch, A. Costa, and S. Engwell (2016). "Reconstructing the plinian and Coignimbrite sources of large volcanic eruptions: A novel approach for the Campanian Ignimbrite". Scientific Reports 6.1. DOI: 10.1038/srep21220.

McCammon, R. B. (1962). "Efficiencies of Percentile Measures for Describing the Mean Size and Sorting of Sedimentary Particles". The Journal of Geology 70.4, pp. 453-465. DoI: 10.1086/626836.

Mellmann, J. (2001). "The transverse motion of solids in rotating cylinders - forms of motion and transition behavior". Powder Technology 118.3, pp. 251270. DOI: $10.1016 / \mathrm{s} 0032-5910(00) 00402-2$.

Mueller, S. B., S. J. Lane, and U. Kueppers (2015). "Labscale ash production by abrasion and collision experiments of porous volcanic samples". Journal of Volcanology and Geothermal Research 302, pp. 163-172. Dor: $10.1016 / \mathrm{j}$. jvolgeores.2015.07.013.

Novák-Szabó, T., A. Á. Sipos, S. Shaw, D. Bertoni, A. Pozzebon, E. Grottoli, G. Sarti, P. Ciavola, G. Domokos, and D. J. Jerolmack (2018). "Universal characteristics of particle shape evolution by bedload chipping". Science Advances 4.3, eaao4946. Dor: $10.1126 /$ sciadv . aao4946.
Ogburn, S. E. and E. S. Calder (2017). "The Relative Effectiveness of Empirical and Physical Models for Simulating the Dense Undercurrent of Pyroclastic Flows under Different Emplacement Conditions". Frontiers in Earth Science 5. Dor: 10.3389/feart. 2017. 00083.

Palladino, D. M. and G. Giordano (2019). "On the mobility of pyroclastic currents in light of deposit thickness and clast size trends". Journal of Volcanology and Geothermal Research 384, pp. 64-74. DoI: $10.1016 / j$. jvolgeores.2019.07.014.

Patel, A., M. Manga, R. J. Carey, and W. Degruyter (2013). "Effects of thermal quenching on mechanical properties of pyroclasts". Journal of Volcanology and Geothermal Research 258, pp. 24-30. DoI: 10.1016/j . jvolgeores. 2013.04.001.

Perugini, D., A. Speziali, L. Caricchi, and U. Kueppers (2011). "Application of fractal fragmentation theory to natural pyroclastic deposits: Insights into volcanic explosivity of the Valentano scoria cone (Italy)". Journal of Volcanology and Geothermal Research 202.3-4, pp. 200-210. DoI: 10.1016/j . jvolgeores. 2011.02 . 008.

Porreca, M., A. Pimentel, U. Kueppers, T. Izquierdo, J. Pacheco, and G. Queiroz (2018). "Event stratigraphy and emplacement mechanisms of the last major caldera eruption on Sete Cidades Volcano (São Miguel, Azores): the 16 ka Santa Bárbara Formation". Bulletin of Volcanology 80.10. DOI: 10.1007 / s00445๑18-1250- 0 .

Roche, O. (2012). "Depositional processes and gas pore pressure in pyroclastic flows: an experimental perspective". Bulletin of Volcanology 74.8, pp. 18071820. DoI: $10.1007 / \mathrm{s} 00445-012-0639-4$.

Rose, W. I. and A. J. Durant (2009). "Fine ash content of explosive eruptions". Journal of Volcanology and Geothermal Research 186.1-2, pp. 32-39. Dor: 10 . 1016/j . jvolgeores. 2009.01.010.

Rowley, P. J., O. Roche, T. H. Druitt, and R. Cas (2014). "Experimental study of dense pyroclastic density currents using sustained, gas-fluidized granular flows". Bulletin of Volcanology 76.9. Dor: 10 . $1007 / \mathrm{s} 00445-014-0855-1$.

Samuelson, J., C. Marone, B. Voight, and D. Elsworth (2008). "Laboratory investigation of the frictional behavior of granular volcanic material". Journal of Volcanology and Geothermal Research 173.3-4, pp. 265279. DoI: $10.1016 / \mathrm{j}$. jvolgeores . 2008.01.015.

Sandeep, C. S. and K. Senetakis (2018). "Effect of Young's Modulus and Surface Roughness on the Inter-Particle Friction of Granular Materials". Materials 11.2 , p. 217. Dor: $10.3390 / \mathrm{ma} 11020217$.

Santos, D. A., M. A. Barrozo, C. R. Duarte, F. Weigler, and J. Mellmann (2016). "Investigation of particle dynamics in a rotary drum by means of experiments and numerical simulations using DEM". Advanced Powder Technology 27.2, pp. 692-703. DoI: 10.1016/ j.apt.2016.02.027. 
Sarocchi, D., R. Sulpizio, J. L. Macıéas, and R. Saucedo (2011). "The 17 July 1999 block-and-ash flow (BAF) at Colima Volcano: New insights on volcanic granular flows from textural analysis". Journal of Volcanology and Geothermal Research 204.1-4, pp. 40-56. DoI: 10. 1016/j . jvolgeores. 2011.04.013.

Sato, H., T. Fujii, and S. Nakada (1992). "Crumbling of dacite dome lava and generation of pyroclastic flows at Unzen volcano". Nature 360.6405, pp. 664-666. Dor: $10.1038 / 360664 a 0$.

Sigurdsson, H. and S. Carey (1989). "Plinian and co-ignimbrite tephra fall from the 1815 eruption of Tambora volcano". Bulletin of Volcanology 51.4, pp. 243-270. DoI: 10.1007/bf01073515.

Sparks, R. S. J. and G. P. L. Walker (1977). "The significance of vitric-enriched air-fall ashes associated with crystal-enriched ignimbrites". Journal of Volcanology and Geothermal Research 2.4, pp. 329-341. Dor: 10 . 1016/0377-0273(77)90019-1.

Sulpizio, R., P. Dellino, D. Doronzo, and D. Sarocchi (2014). "Pyroclastic density currents: state of the art and perspectives". Journal of Volcanology and Geothermal Research 283, pp. 36-65. Dor: 10 . $1016 / j$. jvolgeores.2014.06.014.

Suzuki-Kamata, K. and H. Kamata (1990). "The proximal facies of the Tosu pyroclastic-flow deposit erupted from Aso caldera, Japan". Bulletin of Volcanology 52.5, pp. 325-333. DoI: 10.1007/bf00302046.

Taddeucci, J. and D. Palladino (2002). "Particle sizedensity relationships in pyroclastic deposits: inferences for emplacement processes". Bulletin of Volcanology 64.3-4, pp. 273-284. DOI: 10 . 1007/s00445$002-0205-6$.

Valentine, G. A. (1987). "Stratified flow in pyroclastic surges". Bulletin of Volcanology 49.4, pp. 616-630. DOI: $10.1007 / \mathrm{bf0} 1079967$.

Van den Bogaard, P. and H. Schmincke (1985). "Laacher See Tephra: A widespread isochronous late Quaternary tephra layer in central and northern Europe". Geological Society of America Bulletin 96.12, p. 1554. DoI: $10.1130 / 0016-7606(1985) 96<1554$ : 1stawi $>2$. 0 . $\mathrm{Co} ; 2$.

Wagner, T. and H.-G. Lipinski (2013). "IJBlob: an ImageJ library for connected component analysis and shape analysis". Journal of Open Research Software 1.1.

Walker, G. P. L. (1971). "Grain-Size Characteristics of Pyroclastic Deposits". The Journal of Geology 79.6, pp. 696-714. DOI: 10.1086/627699.

Wilson, G., T. M. Wilson, N. I. Deligne, and J. W. Cole (2014). "Volcanic hazard impacts to critical infrastructure: A review". Journal of Volcanology and Geothermal Research 286, pp. 148-182. DoI: 10.1016/ j. jvolgeores. 2014.08.030. 